\title{
Remote Estimation of Vegetation Parameters Using Narrow band Sensor for Precision Agriculture in Arid Environment
}

\section{El-Sayed Ewis Omran}

Soil and Water Department, Faculty of Agriculture, Suez Canal University, 41522,

Ismailia, Egypt

$\mathbf{T}$

HE PERFORMANCE of hyperspectral (Hyperion) sensor to evaluate and propose potential vegetation indices and to discriminate land cover classes in arid and semi-arid areas was evaluated. The requirements for extracting indices from Hyperion images are to be first compensated for atmospheric correction using FLAASH model. The minimum noise fraction transformation was applied to reduce the data noise and for extracting the extreme pixels. Some pure pixel endmember for the target types and backgrounds was used in this study to account for the Spectral Angle Mapping and the arrived results were validated with field study. Different classes of vegetation wereidentified from the different images: plantation, grassland, crops and trees at initial and senescence stage. The spectral signature for the differentvegetation is identified and used for spectral library generationand image classification. Vegetation, which is in the senescence stage,can bedistinguished visually from the Hyperion image. The overall accuracy was $96 \%, 67 \%$, and $91 \%$, for the 177039 image, 177045 image, and 175042image, respectively. Therefore, Hyperion data havehigh capability for crop types mapping and extraction of useful quantitative information for the purpose of crop monitoring and management. 30 vegetation indices have been assessed in this study. Four indices were proposedto support precision agriculture in an arid environment, which isvegetal cover density (VCDI), vegetal water content (VWCI), vegetal water stress (VWSI), and vegetal discriminating (VDI).Thermal imagerycan help in the detection of different infection in different crops from the first hours ofsuccessful germination of conidiospores. The temperature difference allowed the discrimination between infected and healthy leaves before the appearance of visible necrosis on leaves.

Keywords: Spectral vegetation indices; Hyperion; sensors; Narrowband indices.

\section{Introduction}

Precision agriculture (PA) is a technique, whichinvolves managingagricultural inputs on a site-specific basis by decreasing inputs such as fertilizers, protectthe environment, enhance product quality, and/or toincrease yields. The PA database includes(Venkataratnam, 2001):Crop information (e.g., growth stage, health,nutrient requirement); Soil physical and chemical properties (e.g., depth,texture, nutrient status, salinity, $\mathrm{pH}$ and toxicity, soiltemperature, productivity potential); Microclimatic data (e.g., canopy temperature, wind direction and speed,humidity); Surface and sub-surface drainage conditions; and irrigation facilities (e.g., water availability and planningof other inputs). However, "current soil surveys satisfy few of the soil data of PA. Soil data are not at the appropriate level of detail nor are the indexes required by $\mathrm{PA}$ the same as those provided by soil surveys"(Council., 1997).PA provides means to automate site-specific management using information technology (Auernhammer, 2001). Absence of accurate and easy-to-use soil sensors togather information about a field is one of the mainobstacles to implementing precision farming techniques.A PA system that harnesses advances insensor technology can play a crucial role toward anintelligent crop production system.

In general, remote sensor technology can be classified to broadband (e.g., Landsat and Spot) sensor, and narrowband (e.g., hyperspectral) sensor.A major limitation of broadband sensors is a loss of critical information available due to using 
average spectral information over broadband widths. Narrowband (Hyperion) sensors represent one of the most important technological trends in remote sensing. Hyperion with 242 spectral bands between 400 and $2500 \mathrm{~nm}$ and spatial resolution of $30 \mathrm{~m}$ bear high potentials for agricultural crop discrimination, crop type mapping and detailed land use classification (Tian -Yuan, 2004).Hyper spectral images are characterized by imaging and spectroscopic property, which differentiates the terrestrial features into the unique spectral signature. This property is valuable in classifying land use/cover (LULC) features, especially vegetation and water bodies. Thus, continuous narrowband information of Hyper spectral opens the possibility of identifying even the species level discrimination in vegetation studies.

Hyper spectral data with narrow and continuous bands is considered more sensitive to specific vegetation variations (Darvishzadeh et al., 2008). Narrowband vegetation indices (VIs) can be crucial for providing additional information with significant improvement over broadband vegetation indices in quantifying biophysical and biochemical vegetation characteristics (Darvishzadeh et al., 2008). Hyperion imagery has been the focus of LULC classification (Mathur \& Foody, 2008 and White et al., 2010) and vegetation indices (VIs). Hyperspectral data enable computation of narrowband indices using spectral bands related to biophysical parameters like Leaf Area Index (LAI) (Meroni et al., 2004) and biochemical variables such as chlorophyll (Schaepman, 2007), water (Champagne et al., 2003) and nitrogen (Read et al., 2002). Hyperspectral remote sensing vegetation studies include species composition, crop type, disease and stress studies, nutrients, moisture, light use efficiency and net primary productivity (Thenkabail et al., 2011). These parameters are robust indicators of the physiological and stress conditions that could potentially affect crop yield thus useful for PA purposes (Zarco-Tejada et al., 2005).

Arid and semi-arid areas experience larger spatial variationin vegetation covers mainly due to a high coefficient of variationin precipitation and soil background.Numerous efforts have been done in improving the VIs by determining optimalspectral bands and developing new indices to reduce soil background influences. Nevertheless, to our knowledge, no significant attention has been paid so far to the assessment of the use of Hyperion narrowband VIs in an arid environment.Thus, the main goal of the present work is to evaluate the performance of various types of hyper spectral vegetation indices and improving them by choosing optimal bands. Several research objectives were accomplished to:

1- Retrieve optimal end member, signature spectrum that represents a certain class, to assist the discrimination and classification of vegetation types;

2- Test the current vegetation indices in an arid environment; and

3- Generate effective vegetation indices to support precision agriculture in an arid environment.

\section{Material and Methods}

\section{Study area and data preparation}

Three different areas in Egypt (Fig. 1) are selected for the current study because of its covering different vegetation richness, different locations and availability of suitable Hyperion scene.The first area (image 177039) is located between $30^{\circ} 42^{\prime}-31^{\circ} 00^{\prime} \mathrm{E}$ and $28^{\circ} 52^{\prime}-29^{\circ} 45^{\prime}$ $\mathrm{N}$, which covers the Fayoumand part of Beni-Suef Governorate. The second area (image 175042) is located between $32^{\circ} 32^{\prime}-32^{\circ} 48^{\prime} \mathrm{E}$ and $25^{\circ} 23^{\prime}-$ $26^{\circ} 15^{\prime} \mathrm{N}$, which covers Qena Governorate, and Luxor. The third area (image 177045) is located between $28^{\circ} 10^{\prime}-28^{\circ} 25^{\prime} \mathrm{E}$ and $22^{\circ} 00^{\prime}-22^{\circ} 40^{\prime} \mathrm{N}$, which covers East Oweinat (Fig.1).

Three Hyperion imageries over the studied area acquired on 12/05/2013 (image 175042), 10/05/2015 (image 177045) and 10/10/2013 (image 177039) were obtained. A field survey was performed for the study area in May and October 2014, which were guided with a Global Positioning System (GPS) receiver to be acquainted with different land-use and land-cover patterns. Prior to atmospheric correction, preprocessing and data clean-up were applied to the data. GeoTIFF Hyperion imageries were converted into ENVI format files that contain wavelength, full width half-maximum and bad band information. Hyperion acquired over 400-2500 n min 242 narrowbands each of $10-\mathrm{nm}$ wide bands. The Hyperion data product is radiometrically corrected, geometrically resampled, and registered to a geographic map projection with elevation correction applied. Uncalibrated bands and the bad lines were removed from the image. 
Area of interest was extracted from the subset image. Atmospheric correction for the data has been done using Fast Atmospheric Analyst Line of the Spectral Hypercube (FLAASH) where the radiance was converted to reflectance. Post data processing for classification, including band selection, correction of bad lines, striping pixels and smile. The overall methodology applied in this study is presented in Fig. 2.

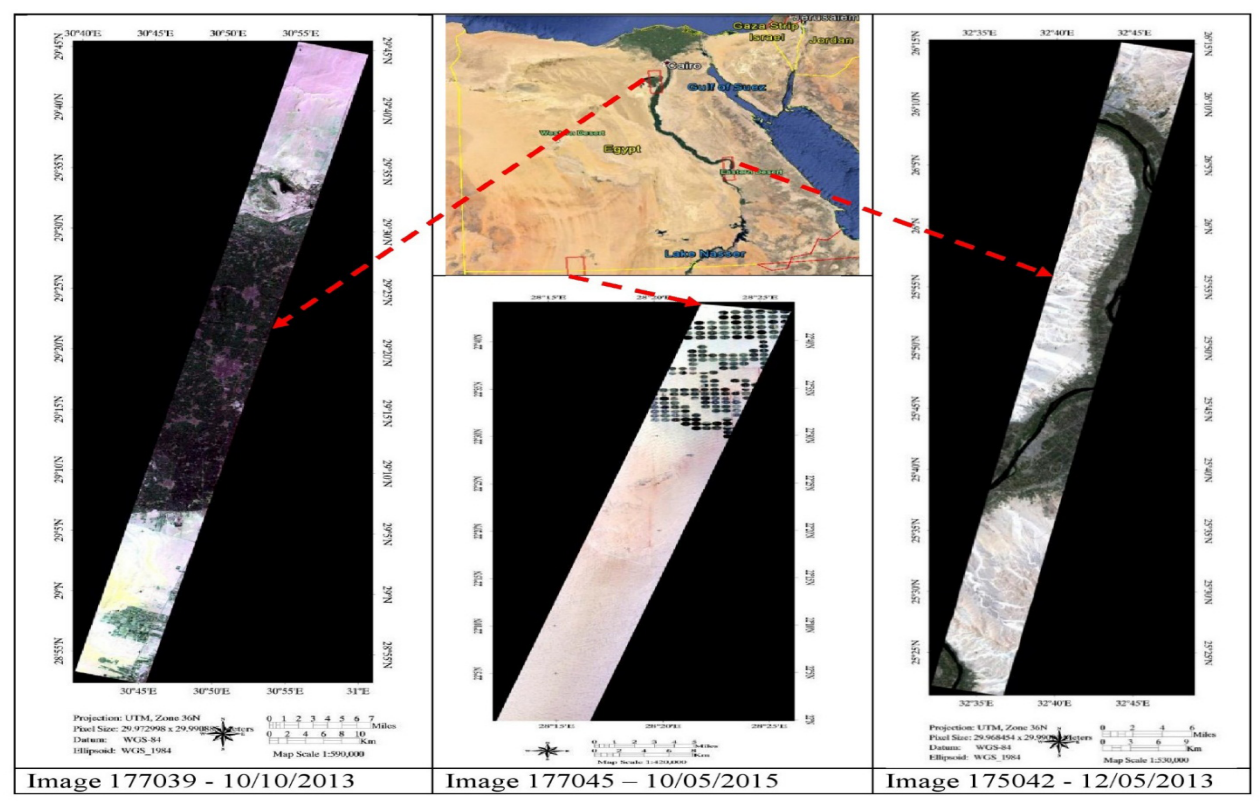

Fig. 1. Footprints and hyperion image of the studied areas

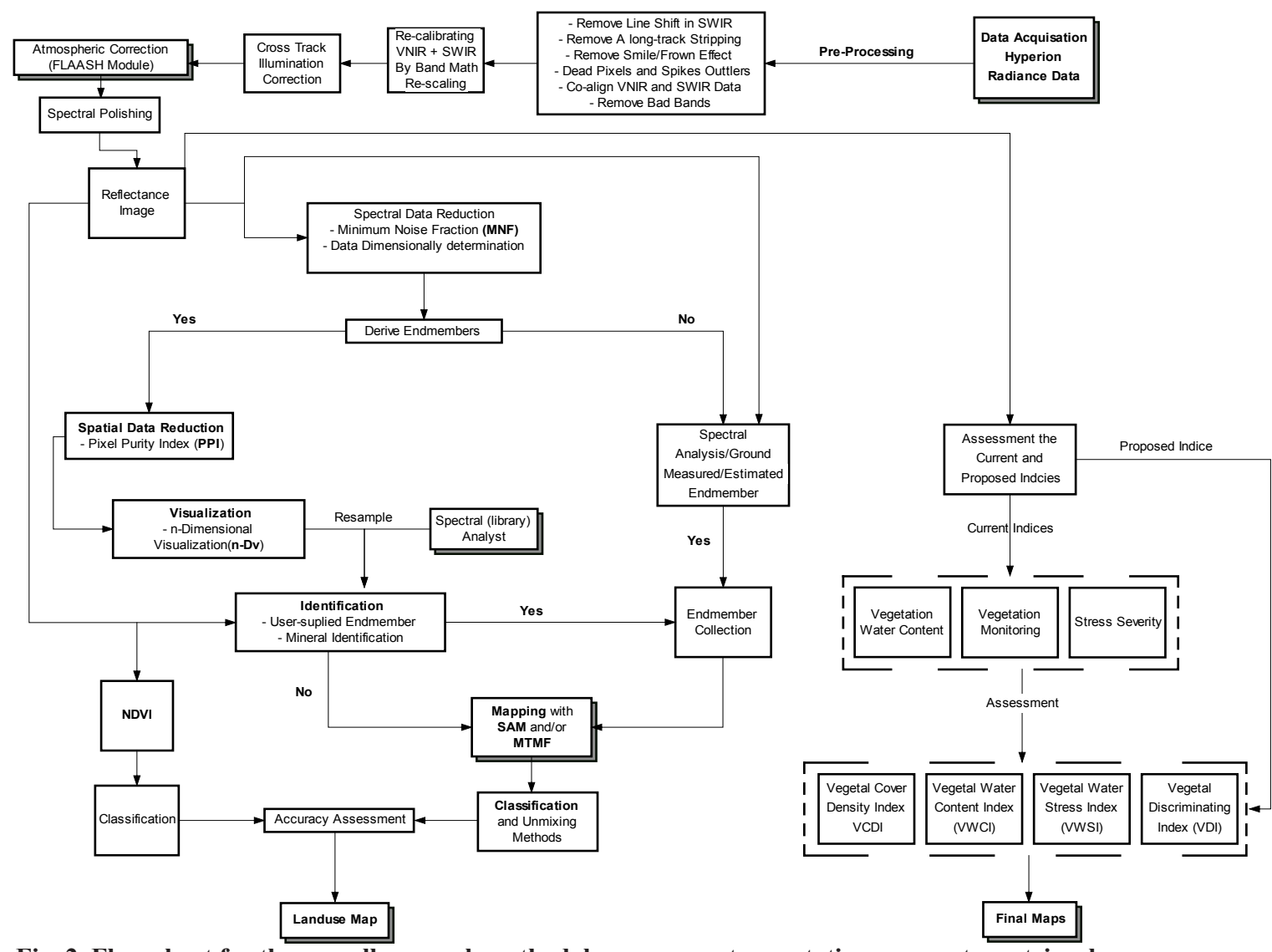

Fig. 2. Flow chart for the overall research methodology on remote vegetation parameter retrieval 


\section{Band selection}

The major problem with the processing of the hyper spectral data is its high number of bands. Band selection is the prerequisite for vegetation indices retrieval by hyperspectral data due to a large amount of interrelated information exists among the bands. Not all spectral bands can be usefully applied to classification or estimation of vegetation parameters. All these factors emphasize the importance of dimensionality reduction or feature extraction from hyper spectral data prior to using that data in classification or estimation of useful parameters. The typical band selection methods include forward selection, backward elimination, and stepwise regression. Lasso and Forward Stagewise are two most popular methods, while the Least Angle Regression (LARS) is one way to implement them (Wu et al., 2005). Lasso implemented by LARS is selected as one of the band selection methods. The band selection in the current study was carried out in two steps. First, select the bands affected by stripping (Fig. 3). A subset of 169 selected bands is listed in Table 1.

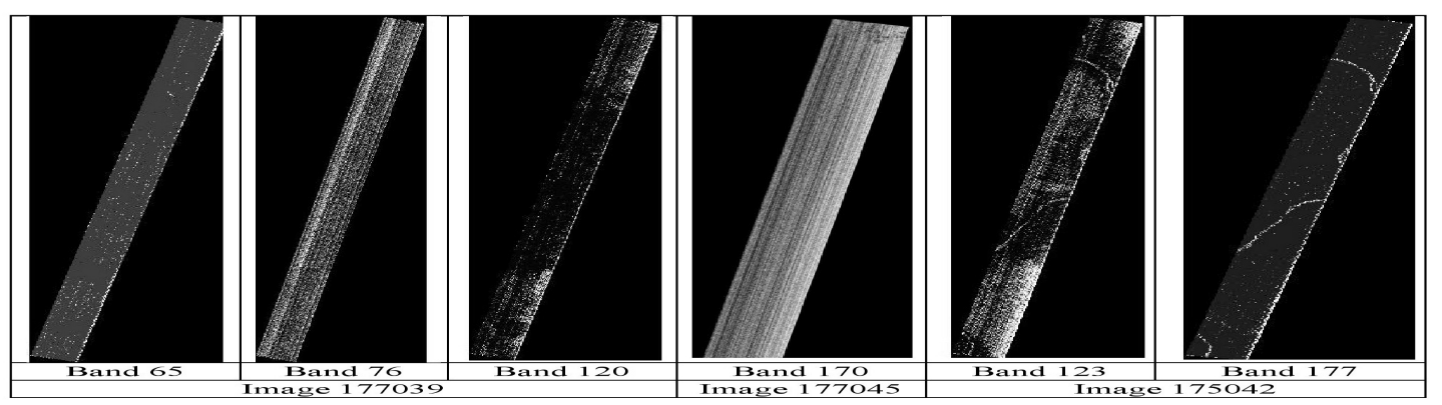

Fig. 3. Hyperion bands for the selected studied areas affected by Striping

TABLE 1. List of the selected 169 bands used for the present study

\begin{tabular}{ccc}
\hline Array & Bands & Wavelength (nm) \\
\hline \multirow{2}{*}{ VNIR } & 9 & 437 \\
& $18-57$ & 528 to 884 \\
& 79 & 996 \\
SWIR & $83-119$ & 1016 to 1336 \\
& $122-164$ & 1366 to 1790 \\
& $183-185$ & 1981 to 2002 \\
& $188-235$ & 2032 to 2506 \\
\hline
\end{tabular}

Second, in Table 2, the final wave bands were selected, which could be considered significant for the study of plant biophysical (e.g., biomass and LAI) or biochemical (e.g., chlorophyll, nitrogen) properties, and their physiology (e.g., stress level). 26 bands were selected. The wave bands from 599.8 to $650.67 \mathrm{~nm}$ were pre-maxima of chlorophyll absorption. Bands 671.02 and $681.2 \mathrm{~nm}$ vary significantly due to changes in factors such as biomass, LAI, soil background, cultivar types, total chlorophyll content, nitrogen, moisture, and stress in plants.

Vegetation indices (VIs) are optical measures of vegetation canopy 'greenness', which give a direct measure of photosynthetic potential. VIs algorithms simplify multi reflective band data into a single value of correlating to physical vegetation parameters (Shwetank et al., 2010). Hyper spectral applications for vegetation studies (Schlerf, 2011) introduced the red edge phenomenon (Bruce et al., 2006), which is correlated with the chlorophyll content in the canopy. In visible wavelengths, healthy green leaf reflects very little solar energy while dead vegetation and soil reflect a greater amount of solar energy, but the reverse is correct for the near infrared region. Plant stress is best detected in red- edge bands centered near $745.25 \mathrm{~nm}$ (Thenkabail et al., 1999). These bands also provide additional information about chlorophyll and nitrogen status of plants. Canopy structure, biomass, and LAI strongly correlate with reflectance near $874.53 \mathrm{~nm}$. The MSNIR and MIR regions beyond $1000 \mathrm{~nm}$ are very sensitive to changes in moisture and biochemical properties such as lignin.

Striping pixels, bad line,smile and atmospheric correction

Bad lines in Hyperion data appear as dark vertical lines (Fig. 3). These pixels have lower digital number (DN) values as compared to their neighboring pixels. These pixels were corrected by replacing in their values with the average values of their immediate left and right neighboring pixels (Ashoori et al., 2008). Vertical stripes are caused by differences in gain and offset of different detectors in push broom-based 
sensors where the image information is valid (not considered as dead pixel). Smile, which exists in all Hyperion datasets, refers to an across-track wavelength shift from center wavelength due to the chance of dispersion angle with field position (Ashoori et al., 2008). For VNIR bands, the shifts range between 2.6-3.5 $\mathrm{nm}$. For SWIR bands, the shifts are less than $1 \mathrm{~nm}$ and are not significant for agricultural applications (Ashoori et al., 2008).
Considering the high spectral resolution of the Hyperion data, the 2.6-3.6 $\mathrm{nm}$ shift of VNIR bands cannot be ignored, in this case the pixel spectra may result in a reduction of classification accuracies. Column mean adjustment in radiance space method was used for smile correction. Atmospheric correction of the Hyperion dataset was performed using FLAASH, an atmospheric correction program (Berk et al., 2005).

TABLE 2. List of the selected 26 bands used for the current study

\begin{tabular}{ll}
\hline Spectrum Region & \multicolumn{1}{c}{ Hyperion Band (Central Wavelength, nm) } \\
\hline Visible & $9(436.99), 25(599.8), 26(609.97), 27(620.15), 29(640.5), 30(650.67), 32(671.02), 33$ \\
& $(681.2)$. \\
Red Edge & $39(742.25), 40(752.43)$. \\
NIR & $42(772.78), 43(782.95), 44(793.13), 45(803.3), 50(854.18), 52(874.53)$. \\
Moisture Sensitive & $86(1003.3), 87(1013.3), 88(1023.4), 89(1033.5), 90(1043.59), 91(1053.69), 92$ \\
NIR (MSNIR) & $(1063.79), 94(1083.99)$. \\
Early MIR (EMIR) & $159(1739.69)$. \\
Far MIR (FMIR) & $185(2002.06)$. \\
\hline
\end{tabular}

Hyperion data reduction and land cover classification

The Hyperion data were evaluated by studying the bandwise image statistics and the dimensionality of data. Mean DN values were computed and plotted to find out the individual statistics. Data dimensionality was studied and reduced using principal component analysis (PCA). It determines percent variability explained in each PCA by its corresponding Eigen values (Pu et al., 2003). The original high dimensional datasets were thus distilled by removing redundant bands and keeping only those that contained most of the information (Thenkabail et al., 2004).

End members refer to the existing of pure features in mixed pixels. Selection and identification of spectral end members in an image are the key point to classification succession. End members were defined using the existing library of reflectance spectra (known end members); or extraction of the purest pixels from the image data itself (derived end members). Because of the access difficulties to spectral library or spectral properties of land cover types of interest, end member data of the known ground cover types were extracted from the Hyperion data. Training points were collected directly on the Hyperion using two approaches. The use of the Pixel Purity Index (PPI) method and a method based on direct selection of well-defined training sites from the Hyperion imagery, assisted by the field-collected training sites.Two-dimensional scatter plots for the bands with the least noise were examined, to help identify the pure end member pixels using PPI method. Collection of image-based end members was performed using the scatterplots of Minimum Noise Fraction (MNF) bands in combination with the PPI technique (Walsh et al., 2008). Representative end members of the different classes were collected for the application of the Spectral Angle Mapper (SAM)(Kruse et al., 1993) algorithmon the Hyperion imagery. SAM performs the classification based on the spectral similarity between image spectra and reference spectra.

The selected hyperion vegetation indices (HVIs)

More than fifty different vegetation indices (VI's) have been reported (Bannari et al., 1995) in the literature.However, after the deployment of hyperspectral sensors, several other VIs have been developed. VIs can be divided into five main categories according to their formula (equation) or according to the potential use of each index (Stagakis et al., 2010): (a) broadband (reflectance) indices; (b) narrow band (hyperspectral) indices; (c) leaf pigment indices; (d) stress indices; and (e) water stress indices. Table 3 provides the list of 30 VIs evaluated in this study. Due to the numerous indices used, only the formula is presented. Additional details for the development and the characteristics of each index can be found in the relative reference shown in Table 3 . As shown in Table 3, similar broadband and narrowband indices exist in the literature. Furthermore, the

Egypt. J. Soil Sci. 58, No. 1 (2018) 
same narrowband vegetation index can be found several times in the literature with a slightly different wavelength. Moreover, some other indices might be modifications of other known indices.

TABLE 3. The selected vegetation indices

\section{Remote estimation of vegetation parameters}

Overall basic and HVI classification

Traditional sampling for vegetation parameter estimation is destructive, expensive, timeconsuming and feasible only for small-scale survey. Vegetation indices calculated from red

\begin{tabular}{|c|c|c|c|c|c|}
\hline Index & Equation & Reference & Index & Equation & Reference \\
\hline $\begin{array}{l}\text { Floating-Position Water Band } \\
\text { Index(FWBI) }\end{array}$ & $\frac{R_{900}}{R_{930}+R_{980}}$ & $\begin{array}{l}\text { Strachan et al., } \\
\text { (2002) }\end{array}$ & $\begin{array}{l}\text { Modified Triangular } \\
\text { Vegetation Index (MTVI2) }\end{array}$ & $\frac{1.5 *\left[1.2 *\left(\mathrm{R}_{800}-\mathrm{R}_{550}\right)-2.5 *\left(\mathrm{R}_{670}-\mathrm{R}_{590}\right)\right.}{\sqrt{\left(2 * \mathrm{R}_{800}+1\right)^{2}-\left(6 * \mathrm{R}_{800}-5 * \sqrt{\mathrm{R}_{670}}\right)-0.5}}$ & $\begin{array}{l}\text { Haboudanea et } \\
\text { al., (2004) }\end{array}$ \\
\hline $\begin{array}{l}\text { Normalized Difference Water } \\
\text { Index (NDWI) }\end{array}$ & $\frac{\mathrm{R}_{858}-\mathrm{R}_{1240}}{\mathrm{R}_{858}+\mathrm{R}_{1240}}$ & McFeeters, $(1996)$ & \begin{tabular}{|l|} 
Renormalized Difference \\
Vegetation Index (RDVI) \\
\end{tabular} & $\mathrm{R}_{800}-\mathrm{R}_{670} / \sqrt{\mathrm{R}_{800}+\mathrm{R}_{670}}$ & $\begin{array}{l}\text { Roujean and } \\
\text { Breon, (1995) }\end{array}$ \\
\hline Modified NDWI (MNDWI) & $\frac{R_{555}-R_{1640}}{R_{555}+R_{1640}}$ & $\mathrm{Xu},(2006)$ & $\begin{array}{l}\text { Enhanced Vegetation Index } \\
\text { (EVI) }\end{array}$ & $\frac{\mathrm{R}_{858}-\mathrm{R}_{645}}{\mathrm{R}_{858}+6 * \mathrm{R}_{645-7.5 * \mathrm{R}_{469+1}}}$ & $\begin{array}{l}\text { Huete et al., } \\
\text { (2002) }\end{array}$ \\
\hline Water Spectral Index (WSI) & $\frac{R_{820}-R_{1450}}{R_{820}+R_{1450}}$ & $\begin{array}{l}\text { Chuvieco, et al., } \\
\text { (2002) }\end{array}$ & \begin{tabular}{|l|} 
Normalized Difference \\
Shortwave-infrared Index \\
(NDSWIR) \\
\end{tabular} & $\frac{R_{858}-R_{1640}}{R_{858}+R_{1640}}$ & $\begin{array}{l}\text { Gerard et al., } \\
\text { (2003) }\end{array}$ \\
\hline Moisture Stress Index (MSI) & $\frac{\mathrm{R}_{1600}}{\mathrm{R}_{820}}$ & $\begin{array}{l}\text { Ceceato et al., } \\
\text { (2001); Hunt and } \\
\text { Rock, (1989) }\end{array}$ & Carter Index (Ctr) & $\frac{\mathrm{R}_{710}}{\mathrm{R}_{760}}$ & $\begin{array}{l}\text { Carter et al, } \\
\text { (1996) }\end{array}$ \\
\hline $\begin{array}{l}\text { Simple Ratio Water Index } \\
\text { (SRWI) }\end{array}$ & $\frac{\mathrm{R}_{858}}{\mathrm{R}_{1240}}$ & $\begin{array}{l}\text { Zarco-Tejada et } \\
\text { al., (2013) }\end{array}$ & $\begin{array}{l}\text { Modified Chlorophyl } \\
\text { Absorption Reflectance } \\
\text { Index (MCARI 1) } \\
\end{array}$ & $\begin{array}{l}{\left[(\mathrm{R} 700-\mathrm{R} 670)-0.2^{*}(\mathrm{R} 700\right.} \\
-\mathrm{R} 550)]^{*}(\mathrm{R} 700 / \mathrm{R} 670)\end{array}$ & $\begin{array}{l}\text { Daughtry et } \\
\text { al., }(2000)\end{array}$ \\
\hline $\begin{array}{l}\text { Shortwave Infrared Water } \\
\text { Stress Index (SIWSI) }\end{array}$ & $\frac{R_{1240}-R_{858}}{R_{1240}+R_{858}}$ & $\begin{array}{c}\text { Fensholt and } \\
\text { Sandholt, (2003) }\end{array}$ & \begin{tabular}{|l} 
Normalized Pigment \\
Chlorophyll Index (NPCI) \\
\end{tabular} & $R_{680}-R_{430} / R_{680}+R_{430}$ & $\begin{array}{c}\text { Merrlyak et } \\
\text { al.,(1999) }\end{array}$ \\
\hline $\begin{array}{l}\text { Normalized Difference } \\
\text { Infrared Index (NDII) }\end{array}$ & $\frac{R_{858}-R_{1650}}{R_{858}+R_{1650}}$ & $\begin{array}{c}\text { Hardisky et al., } \\
\text { (1983) }\end{array}$ & $\begin{array}{l}\text { The Structure Insensitive } \\
\text { Pigment Index (SIPI) }\end{array}$ & $\mathrm{R}_{800}-\mathrm{R}_{445} / \mathrm{R}_{800}-\mathrm{R}_{698}$ & $\begin{array}{c}\text { Penuelas et al., } \\
\text { (1995) }\end{array}$ \\
\hline Liquid Water Index (LWI) & $\frac{R_{1100}-R_{2200}}{R_{1100}+R_{2200}}$ & Seetlig et al., (2008) & $\begin{array}{l}\text { Normalized } \\
\text { Phaeophytinization Index } \\
\text { (NPQI) } \\
\end{array}$ & $\mathbf{R}_{415}-\mathbf{R}_{435} / \mathbf{R}_{415}+\mathbf{R}_{435}$ & $\begin{array}{l}\text { Barnes et al., } \\
\text { (1992) }\end{array}$ \\
\hline Water Band Index (WBI) & R900/R970 & $\begin{array}{l}\text { Sims and Gamon, } \\
\text { (2003) }\end{array}$ & $\begin{array}{l}\text { Photochemical Reflectance } \\
\text { Index (PRI) }\end{array}$ & $\begin{array}{l}\text { PR11 }=\left(R_{528}-R_{567}\right) /\left(R_{528}+R_{567}\right) \\
\text { PR12 }=\left(R_{531}-R_{570}\right) /\left(R_{531}+R_{570}\right)\end{array}$ & $\begin{array}{l}\text { Gamon et al., } \\
\text { (1992) }\end{array}$ \\
\hline Soil Moisture Index (SMI) & $\frac{R_{1550}-R_{1750}}{R_{2080}-R_{2350}}$ & $\begin{array}{c}\text { Musick and } \\
\text { Pelletier, (1986) }\end{array}$ & $\begin{array}{l}\text { Soil- Adjusted Vegetation } \\
\text { Index (SAVI) }\end{array}$ & $1.5\left(\mathrm{R}_{830}-\mathrm{R}_{660}\right) /\left(\mathrm{R}_{830}-\mathrm{R}_{660}+0.5\right)$ & Huete, (1988) \\
\hline $\begin{array}{l}\text { Normalized Difference } \\
\text { Vegetation Index (NDVI) }\end{array}$ & $\frac{R_{800}-R_{640}}{R_{800}+R_{640}}$ & $\begin{array}{l}\text { Sims and Gamon, } \\
\text { (2003) }\end{array}$ & \begin{tabular}{|l} 
Modified Soil Adjusted \\
Vegetation Index (MSAVI)
\end{tabular} & $\frac{(\mathrm{NIR}-\mathrm{Red})}{(\mathrm{NIR}+\operatorname{Red}+\mathrm{L})}(1+\mathrm{L})$ & Qi et al., (1994) \\
\hline $\begin{array}{l}\text { The Normalized Vegetation } \\
\text { Index (NDVI) }\end{array}$ & $\mathrm{R}_{900}-\mathrm{R}_{679} / \mathrm{R}_{900}+\mathrm{R}_{679}$ & Jensen, $(2000)$ & $\begin{array}{l}\text { Optimized Soil- Adjusted } \\
\text { Vegetation Index (OSAVI) }\end{array}$ & $\frac{1.5 *(\mathrm{NIR}-\mathrm{Red})}{(\mathrm{NIR}+\operatorname{Red}+0.16)}$ & $\begin{array}{c}\text { Rondeaux et } \\
\text { al,,(1996) }\end{array}$ \\
\hline Greeness Index(G) & $\mathrm{R}_{554} / \mathrm{R}_{677}$ & . & $\begin{array}{l}\text { Renormalized Difference } \\
\text { Vegetation Index (RDVI) } \\
\end{array}$ & $(\mathrm{NIR}-\operatorname{Red}) / \sqrt{(\mathrm{NIR}+\operatorname{Red})}$ & $\begin{array}{l}\text { Roujean and } \\
\text { Breon,(1995) } \\
\end{array}$ \\
\hline $\begin{array}{l}\text { Modified Triangular } \\
\text { Vegetation Index (MTVI1) } \\
\end{array}$ & $\begin{array}{r}1.2 *\left[1.2 *\left(\mathrm{R}_{800}-\mathrm{R}_{554}\right)-2.5\right. \\
*\left(\mathrm{R}_{670}-\mathrm{R}_{550}\right)\end{array}$ & $\begin{array}{l}\text { Haboudanc et al, } \\
\text { (2004) }\end{array}$ & VogelmannIndices ( $\mathrm{V}_{0 \mathrm{~g}}$ ) & $\begin{array}{c}V_{0 g} \mathrm{~g}=\left(\mathrm{R}_{740}\right) /\left(\mathrm{R}_{720}\right) ; V_{0 \mathrm{~g} 2}=\left(\mathrm{R}_{734}-\mathrm{R}_{747}\right) /\left(\mathrm{R}_{715}+\mathrm{R}_{726}\right) \\
\operatorname{Vog}_{00} \mathrm{~S}=\left(\mathrm{R}_{734}-\mathrm{R}_{747}\right) /\left(\mathrm{R}_{715}+\mathrm{R}_{720}\right)\end{array}$ & $\begin{array}{c}\text { Vogelmann et } \\
\text { al,, (1993) }\end{array}$ \\
\hline
\end{tabular}

and near infrared (NIR) wavelengths are good predictors of vegetation photosynthetic activity and are efficiently correlated to biomass in grasslands (Ren et al., 2011).

However, in arid regions, soil background has more reflectance in the red and near infrared wavelengths, termed the "soil line". Vegetation cover is usually sparse compared to the soil background. Soil and plant spectral signatures tend to mix non-linearly. Thus, arid plants tend to lack the strong red edge found in plants of humid regions due to ecological adaptations to the harsh desert environment. The reflectance of light in the red and near-infrared spectra can influence vegetation index values in dry areas whereas vegetative cover is low (i.e., $<40 \%$ ) and the soil surface is exposed. Based on the normalized difference vegetation index (NDVI), (Huete, 1988) proposed the soil-adjusted vegetation index (SAVI) to minimize and to correct for the influence of soil brightness when vegetative cover is low. Soil adjusted indices such as SAVI, OSAVI and MSAVI have similar accuracies as NDVI (Lawrence and Ripple, 1998) for estimation of vegetation cover fraction of sparse vegetated 
areas.Therefore, there is a need to develop a precise model for use in dry regions for vegetation study.

Spectral indices as a univariate statistical model are one of the most commonly used techniques for characterizing biophysical and biochemical vegetation variables (Chen et al., 2005 and Sims Daniel \& Gamon, 2003). A majorityof the indices developed for structural analysis was formulated for broadband systems. In this study, vegetation properties measured with HVIs can be divided into three main categories (Table 3), although other categorizations might be appropriate for other purposes: 1) Structure; 2) Biochemistry and; 3) Plant physiology/stress. Measured structural properties include fractional cover, green leaf biomass, LAI, and senesced biomass (Sellers, 1985). Many efforts to estimate biomass have been conducted using these soil adjusted and soil-unadjusted vegetation indices during the past decades. Although some Vis have yielded a good performance, accurate assessment of biomass remains a challenge in arid and semi-arid region. The effect of soil noise is the prominent barrier to the derivation of biomass (Eisfelder et al., 2012 and Ren \& Zhou, 2012).

Biochemical properties include water, pigments(chlorophyll, carotenoids, anthocyanins), other nitrogen-rich compounds (e.g. proteins) and plantstructural materials (lignin and cellulose) (Ustin et al., 2009). Ligno-cellulose content indices utilize the Short-Wave-Infrared (SWIR) and wavelengths from 1500 to $1800 \mathrm{~nm}$ and 2000 to $2350 \mathrm{~nm}$.Pigments absorb in the visibleand ultraviolet, with distinct, but overlapping absorption features. Chlorophyll primarily absorbs blue and red light. Anthocyanins absorb all but red light; and many carotenoids are yellow due to strong blue light absorption.Measuring the water status of leaves or shoots is timeconsuming and subject to measurement and sampling errors, especially when data are extrapolated to the whole plant or to the vineyard scale.

Physiological and stress indices measure subtlechanges due to a stress-induced change in the state of xanthophylls (Gamon et al., 1997), changes in chlorophyllcontent (Horler et al., 1983), fluorescence (Zarco-Tejada et al., 2000) or changes in leaf moisture(Hunt and Rock, 1989). Canopy moisture stress indices include wave lengths associated with liquidwater absorption (e.g. 970, $1200 \mathrm{~nm}$ ).Several physiologicalin dicators are used to assess plant water status,or stress, with stomatal conductance, leaf water potential, and transpiration rate. These physiological stress indicators are strongly related to factors such as the relative water content. Water stress in the crops is usually detected only after it becomes visually apparent; this is often too late to prevent a reduction in crop yield.

\section{Understanding the reflectance spectrum of vegetation}

The visible regions of the spectrum, namely $350-490 \mathrm{~nm}$ and $650-700 \mathrm{~nm}$ are the high absorption sections of leaf carotene and chlorophyll (Fig. 4). "Red edge" is the most significant characteristic of vegetation spectrum. The absorption of chlorophyll-a occurs between $680 \mathrm{~nm}$ and $750 \mathrm{~nm}$, locating the biggests lope of a vegetation reflectance curve. Owing to the weak absorption of pigments and liquid water, together with multiple reflections and scattering due to the leaf cell structure, the reflectance between 750 and $1300 \mathrm{~nm}$ maintains high values with an undulating trend. Obvious wave troughs of the reflectance occur at two regions, i.e. $1300-1600 \mathrm{~nm}(1400 \mathrm{~nm})$ and $1830-2008 \mathrm{~nm}(1900 \mathrm{~nm})$, while the wave crests could be found at $1600-1830 \mathrm{~nm}(1650 \mathrm{~nm})$ and 2008-2350nm (2200nm).

Thenkabail et al. (2011) showed that a waveband centered at550 $\mathrm{nm}$ provided excellent sensitivity to plant nitrogen, one centeredat $515 \mathrm{~nm}$ is the best for pigments (carotenoids, anthocyanins), and one at 970 or $1245 \mathrm{~nm}$ is preferred to study plant moisture fluctuations. Lignin, cellulose, protein, and nitrogen have a relatively low reflectance and strong absorption in SWIR bands due to water absorption that masks other absorption features (Thenkabail et al., 2013). Discrimination of subtle biochemical constituents such as the starches, proteins, lignin, and cellulose requires fine ( 3 to $5 \mathrm{~nm}$ ) spectral band widths (Fig. 4) (Thenkabail et al., 2011). Biochemical factors such as chlorophylls a and b, total chlorophyll, carotenoids, anthocyanins, nitrogen, water, and those involved in plant structure (e.g., lignin, cellulose) require similar band widths.

\section{Band selection and indices development}

Accurate estimation of VIs using broadband sensor remains a challenge in arid and semiarid areas due to sparse green vegetation cover (Beeri et al., 2007, He et al., 2006 and Wessels et al., 2006). Based on our field observations, green vegetation cover in our study site was less than $35 \%$. The combined influences of soil background,which may result in poor estimation 
of green aboveground biomass in arid and semiarid grassland have received relatively a little attention. For example, He et al. (2006) developed the L-ATSAVI to minimize soil background influences in a mixed semiarid grassland. As expected, the L-ATSAVI had better estimation than other soil-unadjusted and soiladjusted vegetation indices. Nevertheless, the algorithm of L-ATSAVI contains the soil line parameters, which may limit its popularization, and application.Therefore, in this study, practical VIs, which do not contain the soil line parameters, were proposed. Modified version of VIs applicable in an arid environment were developed. The best narrow bands in different soil types are located in a different spectral region and one index is not suitable for all situations. Wave bands that provide the best information should be selected (Table 4) and the others dropped when studying crops.

Various combinations of the bands in Tables 2 and 4 were used to formulate the indices. Finally, few indices only were eventually used based on how they assisted in better separating the different classification classes, because of the differences in their properties. a

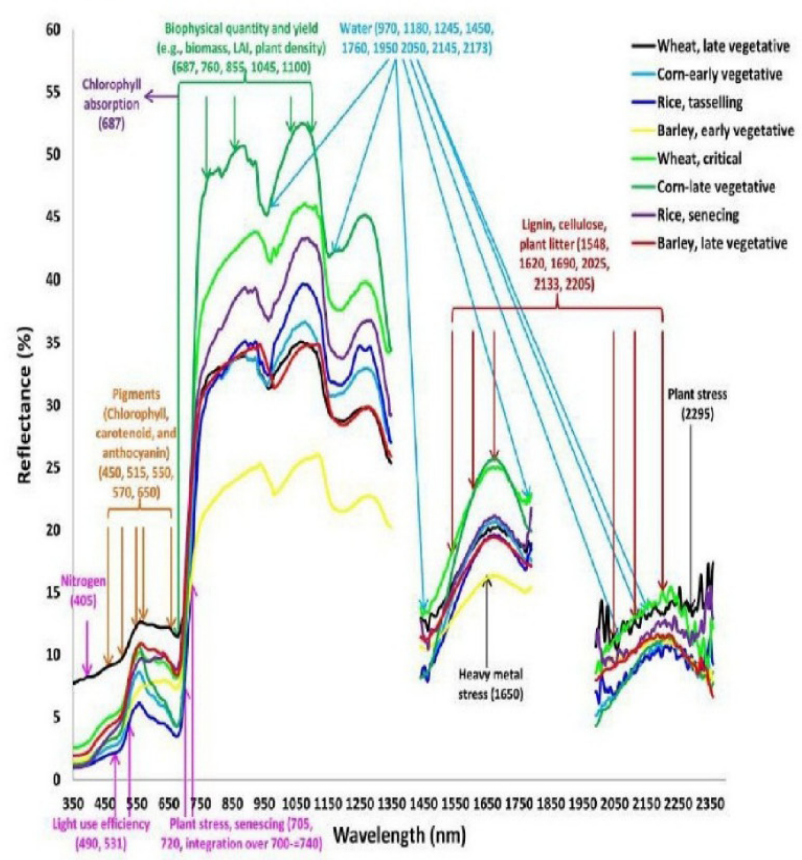

b

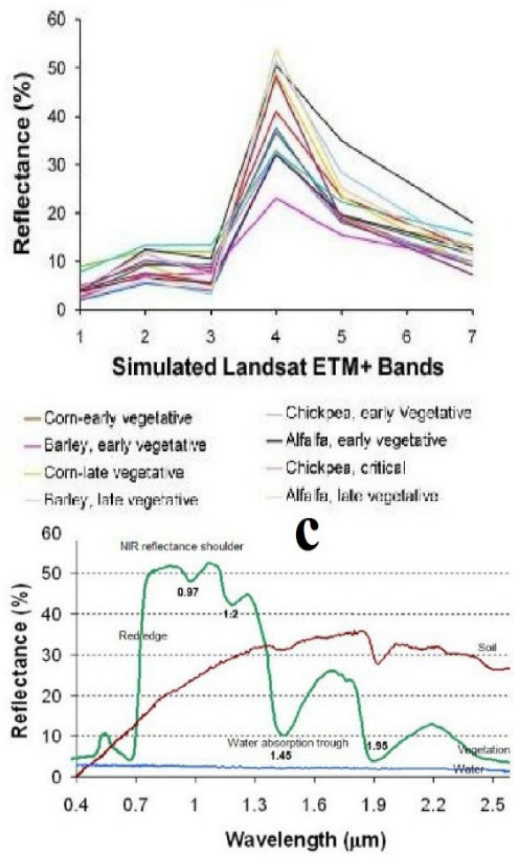

Fig. 4. Hyperspectral reflectance field spectra of eight leading crops, each at two distinct growth stages, are shown for narrowbands (a). Reflectance of vegetation vs. soil and water (b). The simulated ETM+ for Landsat broadband (c). The whole spectral analysis using contiguous bands allows for accurate retrieval of plant biophysical and biochemical quantities (Thenkabail et al., 2013)

TABLE 4. The best 4, 6, 10, 15, and 20 band combinations of hyperspectralnarrowbands for separating or discriminating crop types or classifying them (Thenkabail et al., 2013)

\begin{tabular}{ll}
\hline Best 4 bands & $550,687,855,1180 \mathrm{~nm}$ \\
\hline Best 6 bands & $550,687,855,1180,1650,2205 \mathrm{~nm}$ \\
Best 10 bands & $550,687,720,855,970,1180,1245,1450,1650,2205 \mathrm{~nm}$ \\
Best 15 bands & $515,550,650,687,720,760,855,970,1110,1180,1245,1450,1650,1950,2205 \mathrm{~nm}$ \\
& $490,515,531,550,570,650,687,720,760,855,970,1045,1110,1180,1245,1450,1650$, \\
Best 20 bands & $1760,1950,2205 \mathrm{~nm}$ \\
\hline
\end{tabular}

Egypt. J. Soil Sci. 58, No.1 (2018) 
The first developed index is for vegetation cover (structural properties) as in equation 1.

$$
\begin{aligned}
& \text { Vegetal Cover Density Index }(\mathrm{VCDI})=\mathrm{b} 1^{*} \\
& \frac{\left(\mathbf{R}_{\mathbf{7 6 0}}-\mathbf{R}_{\mathbf{6 5 0}}\right)}{\left(\mathbf{R}_{\mathbf{7 6 0}}+\mathbf{R}_{\mathbf{6 5 0}}\right)}+\mathrm{b} 2 \quad \ldots . \quad \text { Equation } 1
\end{aligned}
$$

Where $\mathrm{b} 1$ and $\mathrm{b} 2$ are constant depending on the best-fit equation calculated using simple linear regression.

The red and near-infrared bands are used for its calculation. High vegetal density has a higher reflectivity in the near infrared and a lower reflectivity in the red. The values vary between -1 and 1. Using this index, different degrees of vegetal covers can be identified (Table 5).

The second developed index is vegetation water content (VWC) (biochemical properties) as in Equation 2.

$\begin{aligned} \text { Vegetal Water Content Index }(\mathrm{VWCI})= & \frac{\left(\mathbf{K}_{\mathbf{1 6 5 0}}-\mathbf{K}_{\mathbf{2 2 0 5}}\right)}{\left(\mathbf{R}_{1650}+\mathbf{R}_{\mathbf{2 2 0 5}}\right)} \\ & \ldots \ldots \text { Equation 2 }\end{aligned}$

Measurement of leaf reflectance may provide a better approach to standardize water status measurements. Reflectance partially depends on the water stored in the leaf cells, especially for NIR and mid-infrared (MIR; 1300- 2500 $\mathrm{nm}$ ) wavelengths (Ceccato et al., 2001). For wavelengths sensitive to water absorption (760, $970,1450,1940$, and $2950 \mathrm{~nm}$ ), leaf and canopy reflectance decreases with increasing tissue water content (Clevers et al., 2010). These wavelength "bands" can be combined in numerous ways to generate vegetation indexes (VIs) related to water status (Bahrun et al., 2003). Various methods have been used in estimating VWC in either statistical approaches (Chen et al., 2005), or physically based (canopy reflectance) models (Clevers et al., 2010). Equation 3 and Table 5 show the VWC.

$\mathrm{VWC} \%=(1-$ Pixel index $) * 100 \ldots \ldots \ldots$ Equation 3

The third developed index was introduced for plant water stress (drought monitoring) of both soil and vegetation surfaces (plant physiology) as in equation 4.

Vegetal Water Stress Index $($ VWSI $)=\frac{\left(\mathbf{R}_{\mathbf{1 6 5 0}}-\mathbf{R}_{\mathbf{4 3 6}}\right)}{\left(\mathbf{R}_{\mathbf{6 5 0}}+\mathbf{R}_{\mathbf{4 3 6}}\right)}$ .....Equation 4

TABLE 5. Degrees of vegetal covers, water content, and description of the water stress conditions

\begin{tabular}{llllll}
\hline VCDI & Cover Density $\%$ & VWC & Water Content \% & VWSI & Description \\
\hline Negative values & $\begin{array}{l}\text { Correspond to clouds or } \\
\text { water bodies } \\
\text { More than } 60 \text { (vigorous } \\
\text { and healthy vegetation) }\end{array}$ & $-0.5--0.3$ & $70-50$ & $0<$ VWSI $\leq 0.3$ & No Stress \\
$0-0.2$ & $60-40$ & $-0.3--0.2$ & $50-30$ & $0.5<$ VWSI $\leq 0.5$ & Low Stress \\
$0.2-0.5$ & $40-20$ & $-0.2-0.0$ & $30-10$ & VWSI $>0.7$ & Highly Stress \\
$0.5-0.7$ & Less than 20 & More than 0.0 & Less than 10 (bare soil) & & \\
$0.7-0.9$ & Fractional to bare soil & & &
\end{tabular}

SWIR and red channels are both sensitive to water variation for soil and vegetation, and the blue channel is less sensitive to moisture changes for both. Therefore, SWIR and red bands can serve as the moisture-measuring channel in index, while the blue band is used as the reference channel or the benchmark for moisture variation. The Blue band is less sensitive to water changes and can serve as the moisture benchmark (Zhang et al., 2013). The combination of the difference between SWIR and blue and the difference between red and blue may maximize moisture variation and have the potential to estimate surface water independence of land-cover types. The overall range of the index is above zero and the larger the value is, the dried the (stress) condition indicated as in Table 5.
The NIR channel was not considered for two reasons. First, NIR reflectance does not have a direct response to waterstress and is readily affected by many factors (leaf structure, LAI, plant density, and plant type), and thus cannot be used as a water-sensitive (or water-measuring) band in VWSI.Second, NIR varies greatly among different land-cover types, especially soil and vegetation. For example, the NIR reflectance of a healthy plant is much higher than that of bare soil. If NIR is used as the reference band, the benchmark of plant moisture variation will be much higher than that of soil, which will make VWSI incomparable among different land-cover types (land-covervariation will overwhelm moisture variation). In contrast, the blue spectrum 
remains at a consistently low value for both vegetation and soil and is least sensitive for vegetation and soil moisture variation compared with NIR, and thus it is preferable to NIR as the reference band in the construction of VWSI.

The fourth developed index is for land cover classification as in Equation 5.

\section{Vegetal Discriminating Index $(\mathrm{VDI})=$}

$\frac{\left(R_{760}-R_{650}\right)}{\left(R_{760}+R_{650}\right)}-\frac{\left(R_{900}-R_{679}\right)}{\left(R_{900}+R_{679}\right)} \ldots$. Equation 5

The computation of this index from the combination of the two indices can assist in better discriminating the land cover. For example, Gong et al. (2003) mentioned that VIs constructed with bands in SWIR and NIR produce a higher correlation with leaf area index than those defined VIs that use red and NIR bands.

\section{Results and Discussion}

\section{Hyperspectral image analyses}

Hyperspectral image analyses were executed to identify different land cover classes and to evaluate and propose vegetation indices. Digital image processing was done including minimum noise transform, (MNF) results, determine data dimensionality, the pixel purity index, n-dimensional visualizer and deriving endmembers, as follows:

\section{Minimum noise fraction (MNF) transform}

Figure 5 shows MNF of the different selected studied areas. The MNF eigen value plot shows the eigen value for each MNF transformed band (Eigen value number). Larger eigen values indicate higher data variance in the transformed band and may help indicate data dimensionality. When the eigen values approach 1, only noise is left in the transformed band, as the noise floor has been scaled to unity in each output MNF band. The dimension of the data indicates the number of intrinsic endmembers contained in the data set since each linearly independent component adds another dimension to spectral data set through mixing. The data dimensionality could be determined from the eigen values by finding where the slope of the eigen value curve breaks and the values falls off to 1 (Fig. 5). This plot was examined and eigen values were compared with the MNF image results. Different end members including soil, vegetation, and water as extracted from the Hyperion data are represented in Fig.5.

\section{Land use/land cover classification}

The atmospherically corrected Hyperion image can distinguish most of the land use/ cover features on the studied areas. Figure 6 shows the land use classification for the study area. The various subclasses of major classes are distinct in Hyperion image, especially like sandy area, salt affected etc. Built up features like rural and compact are clear in the image. Water bodies could be distinguished clearly in Hyperion due to the absorption properties of spectral bands. The different types of vegetation

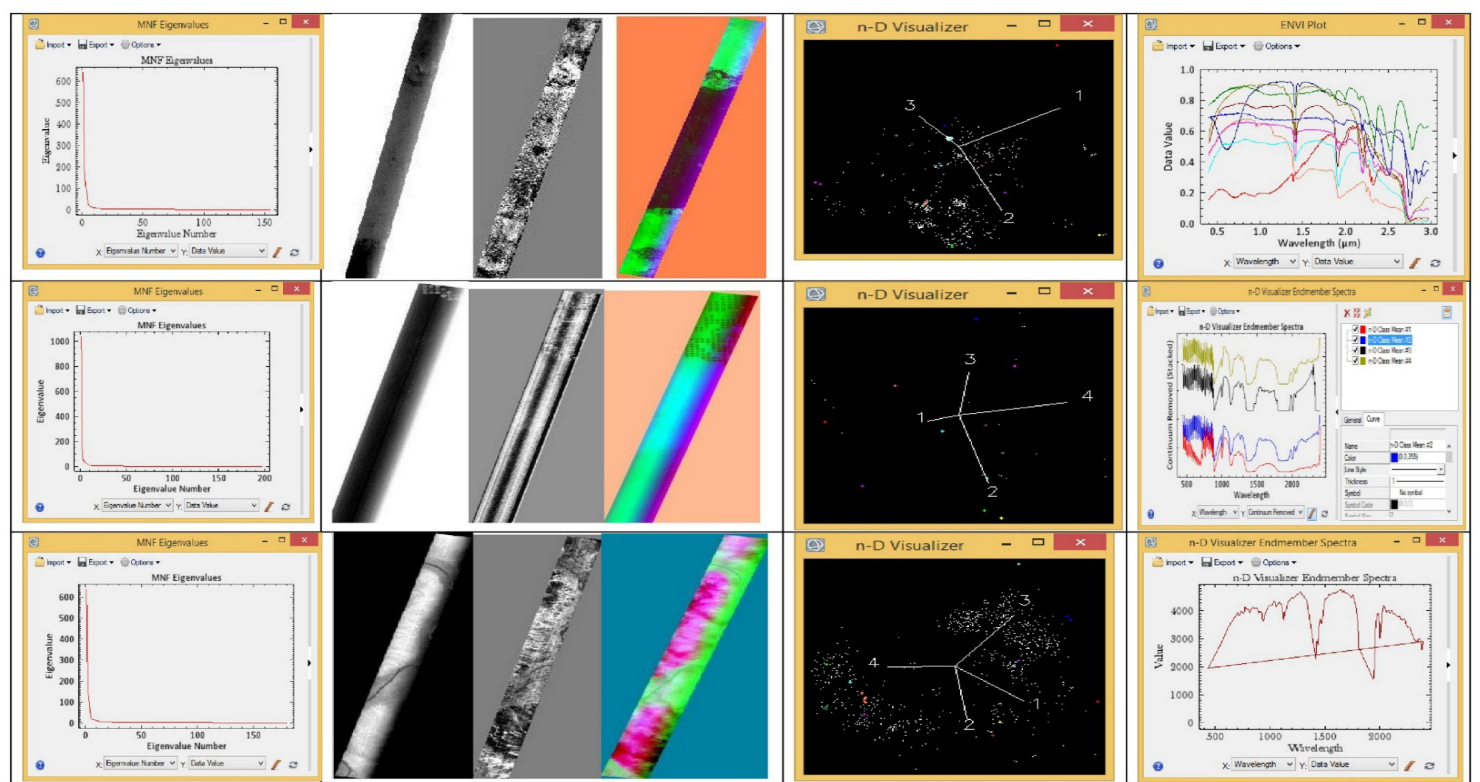

Fig. 5. MNF Eigenvalue Plot, map,PPI plot, n- D visualizer and example of different endmembers extracted from the Hyperion image 177039 (upper), image 177045 (middle), and image 175042 (lower) 
(agriculture, grassland, plantation, crop type) can be distinguished with the varying color intensity. The different types of vegetation and crop classes could be identified in the Hyperion image by color and verified using spectral reflectance, even vegetation health can be identified. Different classes of vegetation were identified from the different images like plantation, grassland and crops at initial and senescence stage, which are depicted in Fig. 6 with a range from class 1 to class 5 (Vegetables (tomatoes, cucumber, onion, squash), water, built-up, clover,and bare soil) for the image 177039 and from class 1 to class 9 (water, clover, sugarcane, rocky area, bare soil, corn, peanut, and tomatoes) for the image 175042 and from class 1 to class 6 (clover, potatoes, peanut, and bare soil) for the image 177045.The spectral signature for the different vegetation is identified and used for spectral library generation and classification of image. Vegetation, which is in the senescence stage can be distinguished visually from the Hyperion image as shown in Fig. 6.

\section{Evaluation of the selected VI}

Figure 7 shows different VIs calculated from the image 175042 as an example. NDVI measuring spectral differences around the red edge is commonly used to represent the health and amount of vegetation. The liquid water index (LWI) estimates water content based on reflectance differences between $1.1 \mu \mathrm{m}$ and $2.2 \mu \mathrm{m}$.A comparison of the spectral characteristics of the channels used in the LWI $(1.1 \mu \mathrm{m}$ and $2.2 \mu \mathrm{m})$ and those used for the NDVI $(0.66 \mu \mathrm{m}$ and $0.86 \mu \mathrm{m})$

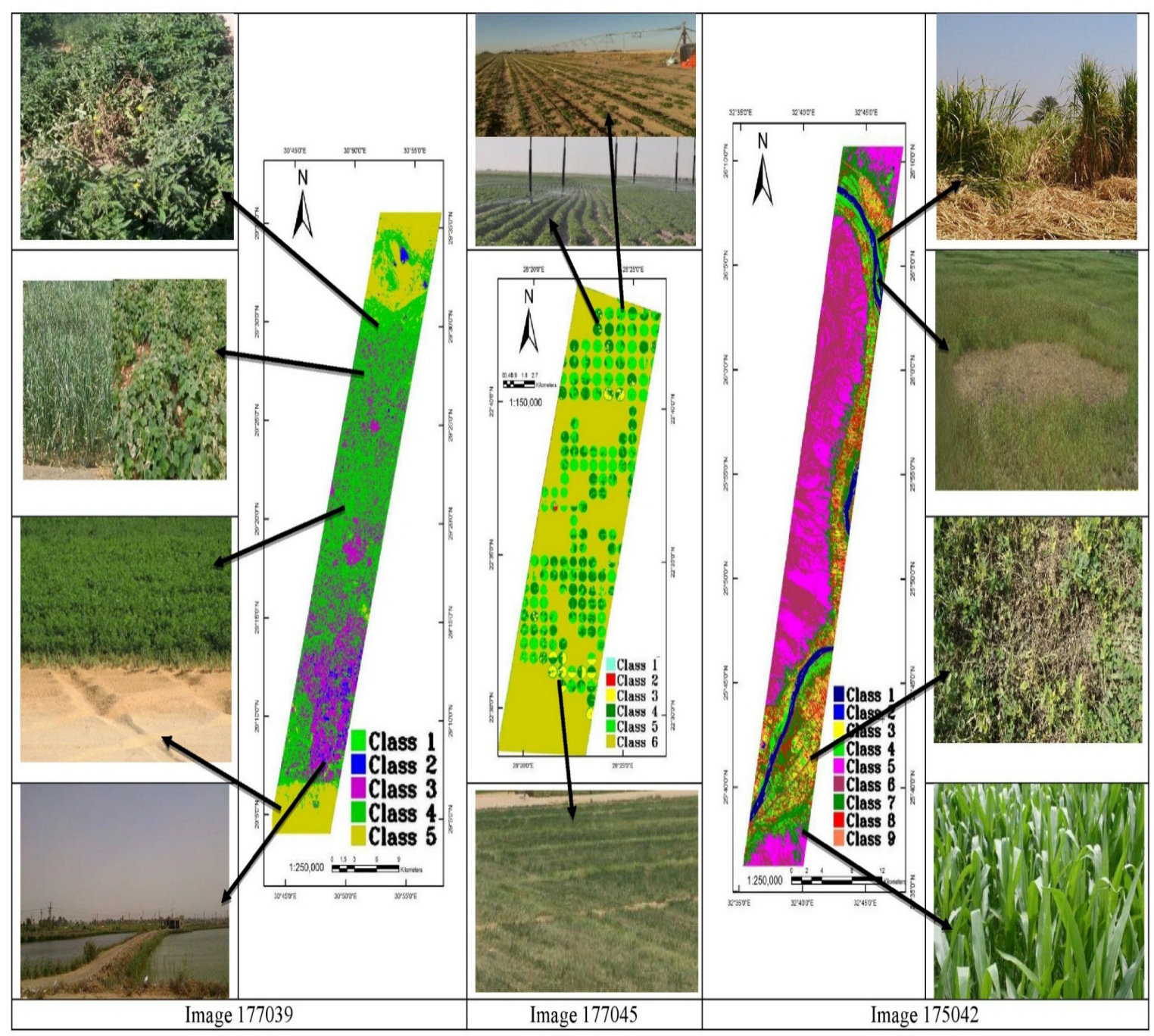

Fig. 6. Classification results identified different vegetation types, and field survey pictures taken from different study areas 
shows similar but reversed trend between dense and sparse or no vegetation conditions (Fig. 4 and 7).While NDVI captures the state of vegetation via chlorophyll content, LWI is indicative of the liquid water content of the vegetation. Therefore, it is not surprising that LWI, like NDVI, has the capability to discriminate between vegetation conditions, but with the added benefit of operating under obscured conditions. The SMI profile also resembles the NDVI profile in overall shape, but has a different scale, since it is calculated as a band ratio rather than a normalized band difference like the NDVI and LWI.The MSI is a simple water ratio index for the estimation of leaf relative water content $(\%)$ and equivalent water thickness (EWT, $\mathrm{g} \mathrm{cm}^{-2}$ ) of different plant species (Hunt and Rock,1989).

It is calculated as $\mathrm{R} 1600 \mathrm{~nm} / \mathrm{R} 820 \mathrm{~nm}$. The accuracies of SRW, NDVI and IPVI were very similar. The indices are low at the soil areas where there is a little or no vegetation. Water absorption bands are centered at 970, 1200, 1450 and 1950nm (Clevers et al., 2010) (Fig. 4) and due to multiplicity of maximum water absorption region, a lot of different indices and techniques have been developed for estimation of vegetation water content (Clevers et al., 2010).

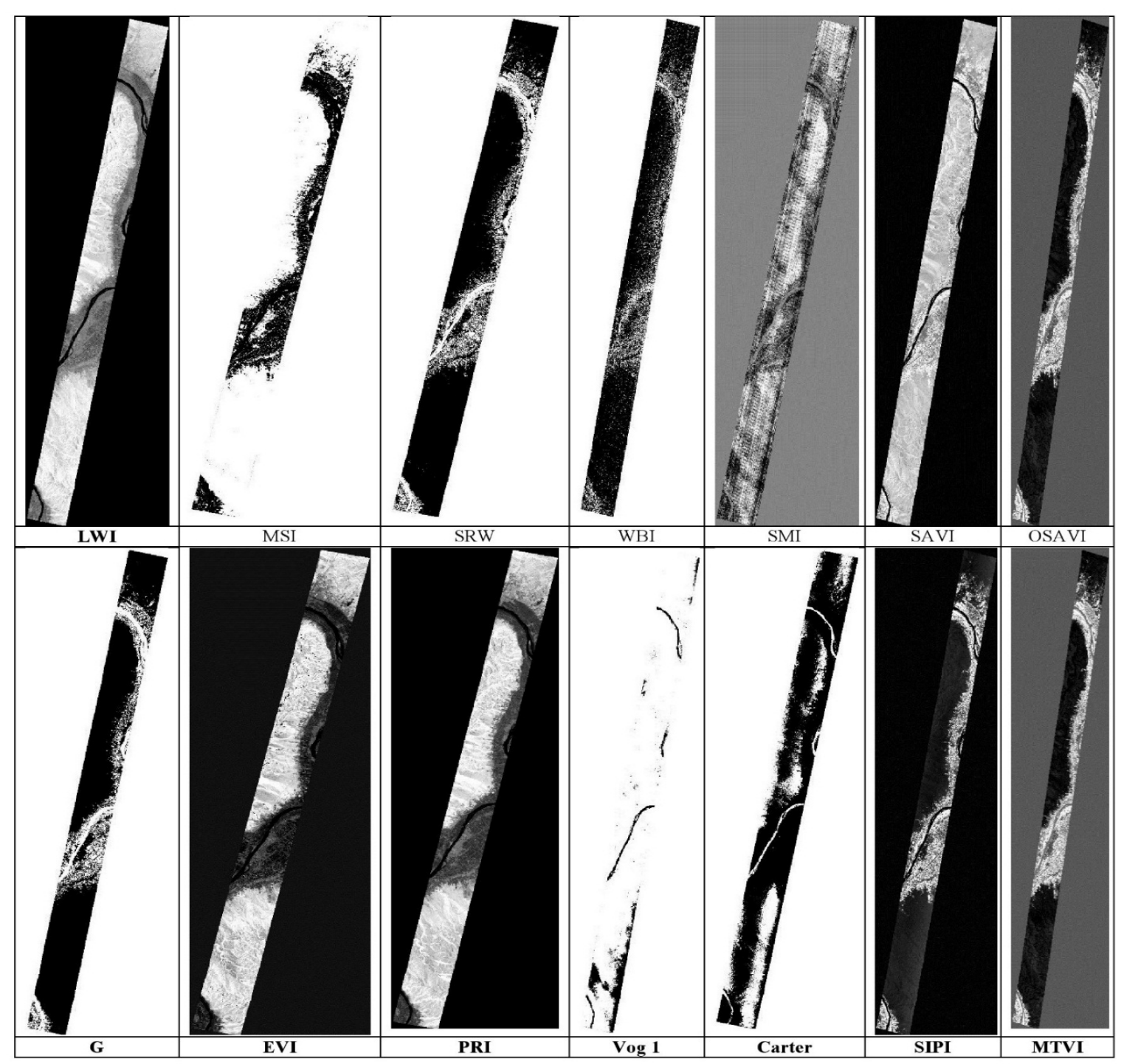

Fig. 7. VIs assessment for image 175042. MSI= Moisture Stress Index, SRWI=Simple Ratio Water Index, LWI=Liquid Water Index, WBI=Water Band Index, SMI= Soil Moisture Index, G=Greeness Index, MTVI=Modified Triangular Vegetation Index, EVI=Enhanced Vegetation Index, SIPI= Structure Insensitive Pigment Index, PRI=Photochemical Reflectance Index, SAVI=Soil- Adjusted Vegetation Index, OSAVI=Optimized Soil- Adjusted Vegetation Index, and Vog=Vogelmann Indices. 
PRI efficient regarding the use of light measures the sensibility of the pigments changes, which are useful for vegetal stress and productivity. The values obtained vary from -1 to 1 , the green vegetation bears values between -0.2 and 0.2 . Foliar pigments, SIPI index uses the relation of the spectral response of the carotenoids and vegetation chlorophyll. An increase of this index indicates stress in the canopy. It is mainly used for monitoring the vegetation health condition and agriculture production.

Triangular indices based on green indices such as GNDVI, TVI, MTVI1, and MTVI2 have the least accuracies. The last three mentioned triangular indices had been recommended for hyperspectral sensors (Haboudane et al., 2004). Although, DVI and RDVI are the most accurate indices to determine vegetation cover fraction, but their accuracies are not proper in dry and sparsely vegetated areas. However,the algorithms of TSAVI, ATSAVI and PVI contain the slope and intercept of the soil line, which greatly limit their applications. In SAVI, L indicates the soil-brightness dependent correction factor that compensates for differences in soil background condition, $\mathrm{L}=1$ low vegetation densities, $\mathrm{L}=0.5$ intermediate vegetation densities and $\mathrm{L}=0.25$ higher densities. The dynamic range of the inductive MSAVI was slightly lower than that of the empirical $\mathrm{L}$ function due to differences in $\mathrm{L}$ boundary conditions. The value of (OSAVI) 0.16 in this formula was found to produce a satisfactory reduction in soil noise, both for low and high vegetation cover.

Vigorousness, which is related to the biomass or the vegetation vigor, is calculated using the red and near-infrared bands. High vigor areas (vegetal density) have a higher reflectivity (response) in the near infrared and a lower reflectivity in the red. Delivered vigorousness values of this relation vary between -1 and 1 . The value comes closer to 1 is indicating vigorous and healthy vegetation. The values closed to zero are related to bare soil. Negative values generally correspond to clouds or water bodies. Using this index, we can identify different degrees of vegetal covers.

\section{Accuracy assessment}

The accuracy of the classified images was assessed using overall accuracy and kappa coefficient. Classification results of the analysis can be seen in Tables $6-8$.
Early detection of agricultural stress and plant disease

Figure 8 shows the agricultural stress and healthy vegetation calculated for the different study areas, which allow identifying the stress condition of the cultivation. High heterogeneity was established in the health condition in the cultivated area, identifying specific sites with a high stress degree.

In Fig. 8, there were different identified sites in image 177039 with trees older than fifteen years, which was assessed in the field survey, with different values of agricultural stress. As the plant grows the visible and mid-IR reflectance decreases, the near-IR reflectance increases, and the reverse is observed during senescence. Red edge is the abrupt increase in reflectance from visible to near infrared defined by the point of maximum slope. The wavelength position of the red edge is Red Edge InflectionPoint (REIP) is between 680 and 740nm. REIP depends on the amount of chlorophyll seen by the sensor and is characterized by chlorophyll concentration and LAI. An increase in chlorophyll concentration increases the chlorophyll consequently the REIP shifts towards longer wavelength-redshift. Decrease in chlorophyll absorption will shift the REIP towards wavelength-blue shift (Schlerf, 2011).Leaf temperature isan indicator of stomatal conductance because stomatal opening increases withdecreasing temperature due to evaporation. Therefore, physiological responsesof Sugarcane leaves (image 175042, Fig. $6 \& 8$ ) to biotic stress, such as fungus can easily bemonitored using thermal imaging due to the spore density, which covers the leafsurface and causes a masking effect. This might be the reason of decreasingleaf surface temperature of the infected plants. Xu et al. (2006) shows that a presymptomatic decrease in leaf temperature about $0.5-1.3{ }^{\circ} \mathrm{C}$ lower than the healthy leaves. Thermal imagerycan help in the detection of powdery infection in wheat from the first hours ofsuccessful germination of conidiospores as shown in image 177039 (Figures 6 and 8). The temperature difference allowed the discrimination between infected and healthy leaves before the appearance of visible necrosis on leaves.

\section{Application of the proposed indices}

This paper addresses the problem of remote estimation of cover density, water content, water stress, and cover discriminating. Percent ground cover is defined as the percentage of an area on the earth's surface occupied by vegetation, including grasses, herbaceous plants, shrubs, and trees. Equation 6has been used to estimate percent vegetation cover in an image 177039 as 
TABLE 6. Accuracy of different cover discrimination for the 177039 image

\begin{tabular}{lcccccc}
\hline \multirow{2}{*}{ Class } & \multicolumn{5}{c}{ Test Pixels } & \multicolumn{2}{c}{ Total } \\
\cline { 2 - 6 } & Class 1 & Class 2 & Class 3 & Class 4 & Class 5 & \\
\hline Unclassified & 0 & 0 & 0 & 0 & 0 & 0 \\
Class 1 & 1560 & 95 & 0 & 0 & 0 & 1655 \\
Class 2 & 73 & 1310 & 82 & 41 & 0 & 1506 \\
Class 3 & 0 & 81 & 480 & 56 & 73 & 690 \\
Class 4 & 84 & 92 & 29 & 910 & 53 & 1168 \\
Class 5 & 45 & 57 & 120 & 77 & 680 & 979 \\
Total & 1762 & 1635 & 711 & 1084 & 806 & 5998 \\
Overall accuracy & & & $\mathbf{9 6 . 4 5}$ & & & \\
Kappa Value & & $\mathbf{0 . 9 3}$ & & & & \\
\hline
\end{tabular}

TABLE 7. Accuracy of different cover discrimination for the 177045 image

\begin{tabular}{lcccccc}
\hline Class & \multicolumn{3}{c}{ Test Pixels } & \multicolumn{3}{c}{ Total } \\
\cline { 2 - 6 } & Class 1 & Class 2 & Class 3 & Class 4 & Class 5 & Class 6 \\
\hline Unclassified & 510 & 320 & 110 & 96 & 84 & 490 \\
Class 1 & 1200 & 39 & 119 & 34 & 97 & 0 \\
Class 2 & 36 & 1539 & 64 & 98 & 134 & 34 \\
Class 3 & 0 & 45 & 1753 & 98 & 110 & 87 \\
Class 4 & 93 & 74 & 132 & 563 & 19 & 98 \\
Class 5 & 24 & 95 & 0 & 0 & 874 & 43 \\
Class 6 & 116 & 0 & 91 & 82 & 34 & 1032 \\
Total & 1979 & 2112 & 2269 & 971 & 1352 & 1784 \\
Overall accuracy & & & $\mathbf{6 7 . 1 2}$ & & 1036 \\
Kappa Value & & & $\mathbf{0 . 6 4}$ & & 10467 \\
\hline
\end{tabular}

TABLE 8. Accuracy of different cover discrimination for the 175042 image

\begin{tabular}{|c|c|c|c|c|c|c|c|c|c|c|}
\hline \multirow[t]{2}{*}{ Class } & \multicolumn{9}{|c|}{ Test Pixels } & \multirow[t]{2}{*}{ Total } \\
\hline & Class 1 & Class 2 & Class 3 & Class 4 & Class 5 & Class 6 & Class 7 & Class 8 & Class 9 & \\
\hline Unclassified & 102 & 94 & 46 & 38 & 99 & 104 & 37 & 38 & 120 & 678 \\
\hline Class 1 & 1205 & 0 & 45 & 94 & 34 & 46 & 36 & 90 & 14 & 1564 \\
\hline Class 2 & 92 & 499 & 83 & 0 & 32 & 0 & 93 & 56 & 86 & 941 \\
\hline Class 3 & 129 & 63 & 429 & 0 & 0 & 63 & 23 & 25 & 32 & 764 \\
\hline Class 4 & 93 & 28 & 209 & 1194 & 127 & 65 & 50 & 84 & 83 & 1933 \\
\hline Class 5 & 92 & 43 & 25 & 67 & 1305 & 97 & 65 & 43 & 73 & 1810 \\
\hline Class 6 & 0 & 65 & 78 & 99 & 69 & 1294 & 87 & 0 & 0 & 1692 \\
\hline Class 7 & 0 & 45 & 76 & 54 & 87 & 23 & 783 & 0 & 0 & 1068 \\
\hline Class 8 & 54 & 87 & 0 & 0 & 87 & 35 & 45 & 920 & 124 & 1352 \\
\hline Class 9 & 23 & 67 & 54 & 35 & 86 & 129 & 32 & 98 & 1219 & 1743 \\
\hline Total & 1790 & 991 & 1045 & 1581 & 1926 & 1856 & 1251 & 1354 & 1751 & 13545 \\
\hline $\begin{array}{l}\text {-Overall } \\
\text { accuracy }\end{array}$ & & & & & 80.93 & & & & & \\
\hline $\begin{array}{l}\text {-Kappa } \\
\text { Value }\end{array}$ & & & & & 0.78 & & & & & \\
\hline
\end{tabular}

a selected example for the current study. Figure 9 depicts the relationship between $\mathrm{X}$, which is

equal to, and percent covers for the 25 field sites. The solid line traces the best-fit equation calculated using simple linear regression:

Vegetati $\frac{\left(\mathbf{R}_{760}-\mathbf{R}_{650}\right)}{\left(\mathbf{R}_{760}+\mathbf{R}_{650}\right)} 38 * \frac{\left(\mathbf{R}_{760}-\mathbf{R}_{650}\right)}{\left(\mathbf{R}_{\mathbf{7 6 0}}+\mathbf{R}_{650}\right)}$

$$
+0.1674 \ldots \ldots \ldots \ldots . . . \text { Equation } 6
$$

The model was used to produce a percent cover map of the study area as shown in Fig.10.

\section{Conclusion}

Three objectives were identified in the introductory part of this paper. The first objective 


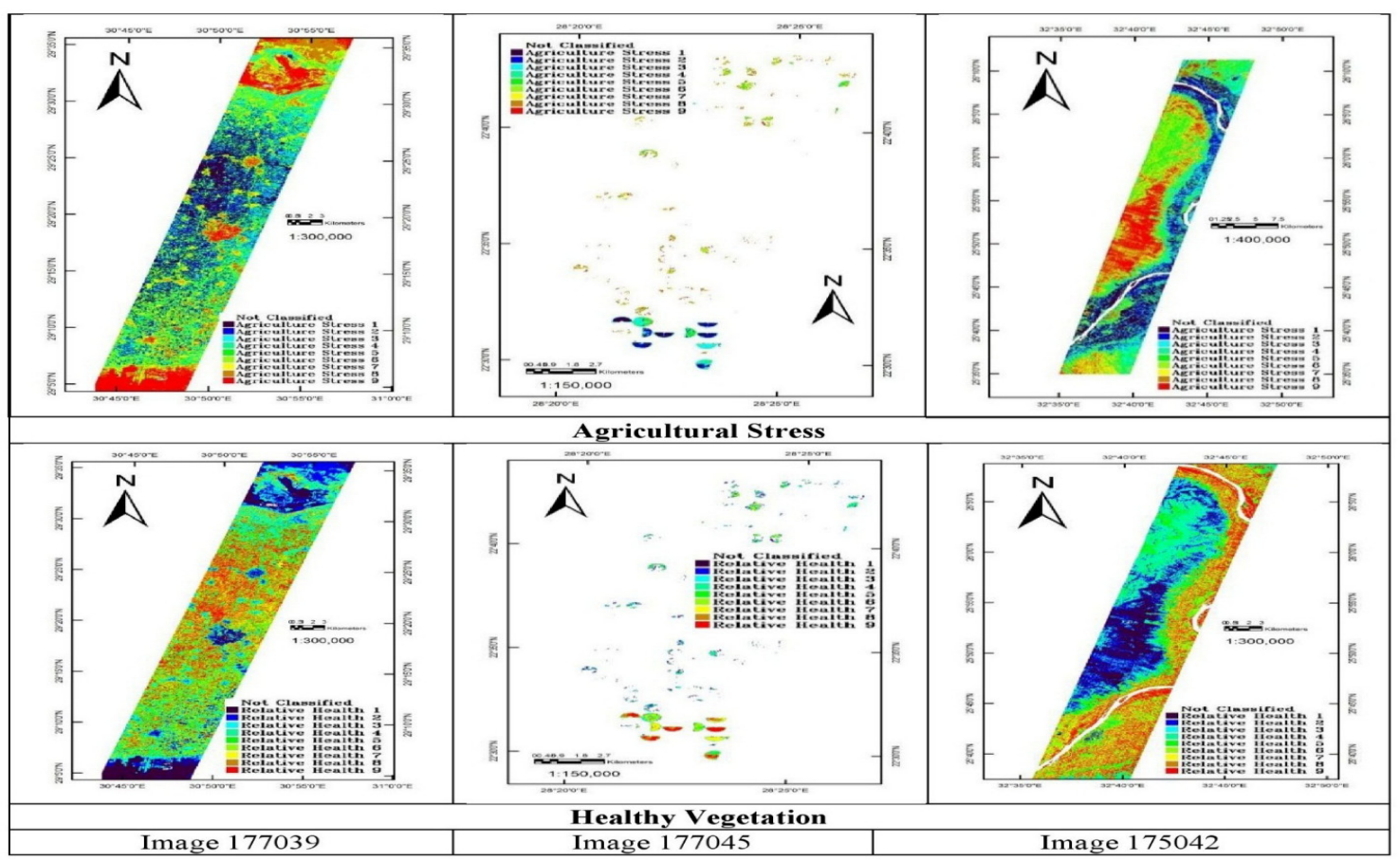

Fig. 8. Agricultural stress and healthy vegetation for the different study areas.

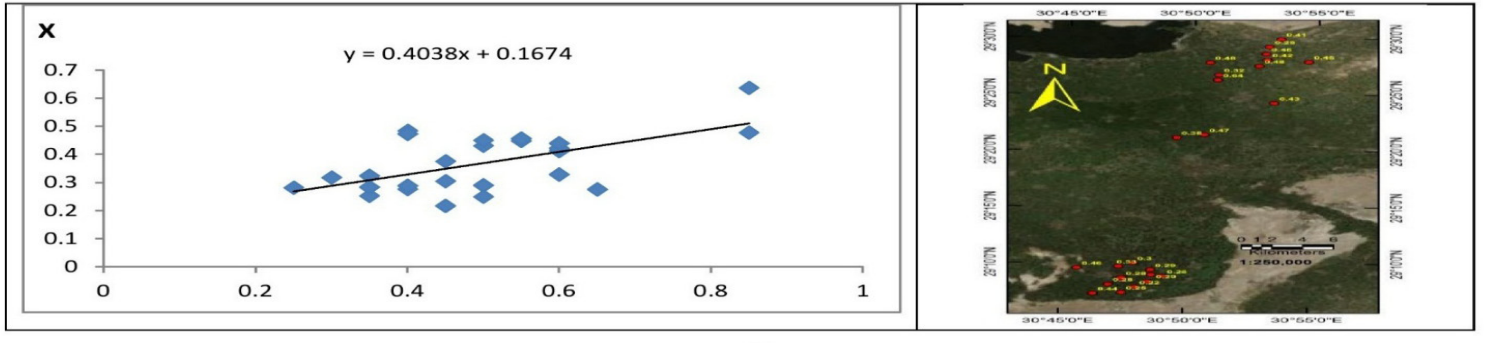

Fig. 9. Evaluation of vegetation percent for a total of 25 sites, whichwere sampled in October 2014

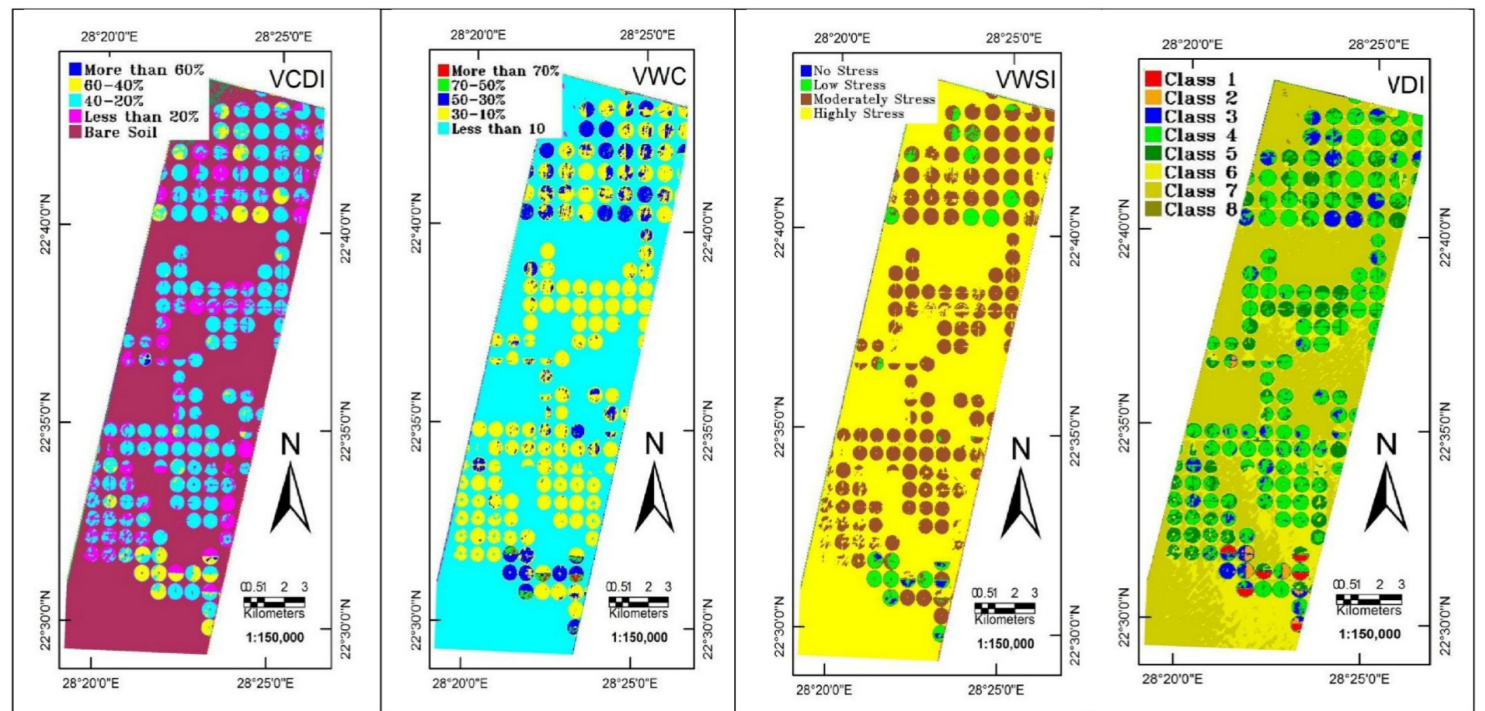

Fig. 10. Proposed Indices for prediction of vegetal cover density (VCDI), vegetal water content (VWCI), vegetal water stress (VWSI), and vegetal discriminating (VDI) 
is to retrieve the optimal endmember, signature spectrum thatrepresents a certain class, to assist the discrimination and classification of vegetation types. Different classes of vegetation wereidentified from the different images likea plantation, grassland and crops at initial and senescence stage. The spectral signature for the differentvegetation is identified and used for spectral library generationand image classification. Vegetation, which is in the senescence stage,can bedistinguished visually from the Hyperion image. The overall accuracy was $96 \%, 67 \%$, and $91 \%$, for the 177039 image, 177045 image, and 175042image respectively.Hyperion data for crop types mapping and extraction of useful quantitative information for the purpose of crop monitoring and management is recommended because of its high capability.

The second objective was to test the current vegetation indicesin an arid environment. In this research, 30 vegetation indices have been assessed. A comparison of the spectral characteristics of the channels used in the LWI $(1.1 \mu \mathrm{m}$ and $2.2 \mu \mathrm{m})$ and those used for the NDVI $(0.66 \mu \mathrm{m}$ and 0.86 $\mu \mathrm{m})$ shows similar but reversed trend between dense and sparse or no vegetation conditions. While NDVI captures the state of vegetation via chlorophyll content, LWI is indicative of the liquid water content of the vegetation.

SMI profile resembles the NDVI profile in overall shape, but has a different scale, since it is calculated as a band ratio rather than a normalized band difference like the NDVI and LWI.The accuracies of SRW, NDVI andIPVI were very similar.The indices are low at the soil areas where there is little or no vegetation.

The last objective was to generate effective vegetation indices to support precision agriculture in an arid environment. Four indices were proposed, which were:vegetal cover density (VCDI), vegetal water content (VWCI), vegetal water stress (VWSI), and vegetal discriminating (VDI).Finally, based on the present study, the temperature difference in thermal imageryallowed the discrimination between the infected (e.g., powdery diseases)and healthy leaves from the first hours ofsuccessful infectionbefore the appearance of visible necrosis on the leaves. Therefore, our ongoing researchis currently focused on developingan early warning system using a multisensing systemsand a multi-sensor platform for real-time diseases detection.

\section{References}

Ashoori, H., Fahimnezhad, H., Alimohammadi, A. and Soofbaf, S.R. (2008) Evaluation of the Usefulness of Texture Measue for Crop Type Classification by Hyperion Data. The International Archives of The Spatial Information Sciences, Part B8, Beijing XXXVII:999-1006.

Auernhammer, H. (2001) Precision farming-the environmental challenge. Comput. Elect. Agric. 30,41-33.

Bahrun, A., Mogensen V.O., C.R. J. (2003) Water stress detection in field-grown maize by using spectral vegetation index. Comm. Soil Sci. Plant Anal. 34,65-79.

Bannari, A., Morin, D., Huette, A.R. and Bonn, F. (1995) A review of vegetation indices. Remote Sens. Environ. 13, 95-120.

Barnes, J.D., Balaguer, L., Manrique, E., Elvira, S. and Davison, A.W. (1992) A reappraisal of the use of DMSO for the extraction and determination of chlorophylls a and b in lichens and higher plants. Environmental Experimental Botany, 2, 85-100.

Beeri, O., Phillips, R., Hendrickson, J., Frank, A.B. and Kronberg, S. (2007) Estimating forage quantify and quality using aerial hyperspectral imagery for northern mixed-grass prairie. Remote Sensing of Environment, 110, 216-225.

Berk, A., Anderson, G.P., Acharya, P.K., Bernstein, L.S., Muratov, L., Lee, J., Fox, M.J., Adler-Golden, S.M., Chetwynd, J.H., Hoke, M.L., Lockwood, R.B., Cooley, T.W. and Gardner, J.A. (2005) MODTRAN5: a Reformulated Atmospheric Band Model with Auxiliary Species and Practical Multiple Scattering Options. Proc. SPIE 5655, Multispectral and Hyperspectral Remote Sensing Instruments and Applications II, 88 (January 20, 2005); doi:10.1117/12.578758

Bruce, L., Mathur, A. and Byrd, J. (2006) Denosing and wavelet based feature extraction of MODIS multi temporal vegetation signatures. GI Science and Remote Sensing, 43,170-180.

Carter, G.A., Dell, T.R. and Cibula, W.G. (1996) Spectral reflectance characteristics and digital imagery of a pine needle blight in the southeastern United States. Canadian Journal of Forest Research, 26,402-407.

Ceccato, P., Flasse, S., Tarantola, S., Jacquemoud, S. and Gregoire, J.M. (2001) Detecting vegetation 
leaf water content using reflectance in the optical domain. Remote Sensing of Environment, 77, 22-33.

Champagne, C.M., Staenz, K., Bannari, A., Mc Nairn, H. and Deguise, J.C. (2003) Validation of hyperspectral curvefitting model for the estimation of plant water content of agricultural canopies. Rem. Sens. Envir. 87,148-160.

Chen D., Huang J. and Jackson T. (2005) Vegetation water content estimation for corn and soybeans using spectral indices derived from MODIS nearand short-wave infrared bands Remote Sensing of Environment, 98, 225 - 236.

Chuvieco, E., Riaño, D. and Aguado, I. (2002) Estimation of fuel moisture content from multitemporal analysis of Landsat Thematic Mapper reflectance data: applications in fire danger assessment. Int J Remote Sens, 23, 2145-2162.

Clevers, J.G.P.W., Kooistra, L. and Schaepma, M.E. (2010) Estimating canopy water content using hyperspectral remote sensing data International Journal of Applied Earth Observation and Geoinformation, 12, 119-125.

Council, N.R. (1997) Precision Agriculture in the $21^{\text {st }}$. National Academy Press. Washington, DC.

Darvishzadeh, R., Skidmore, A., Schlerf, M., Atzberger C., Corsi, F. and Cho, M. (2008) LAI and chlorophyll estimation for a heterogeneous grassland using hyperspectral measurements. Isprs Journal of Photogrammetry and Remote Sensing , 63, 409-426.

Daughtry, C.S.T., Walthall, C.L., Kim, M.S., Brown de Colstoun, E., McMurtrey, III J.E. (2000) Estimating corn leaf chlorophyll concentration from leaf and canopy reflectance. Remote Sens. Environ. 74,229239.

Eisfelder, C., Kuenzer, C. and Dech, S. (2012) Derivation of biomass information for semi-arid areas using remote-sensing data. International Journal of Remote Sensing, 33, 2937-2984.

Fensholt, R. and Sandholt, I. (2003) Derivation of a shortwave infrared water stress index from MODIS near- and shortwave infrared data in a semiarid environment. Remote Sens Environ. 87,111-121.

Gamon J. A., Serrano, L. and Surfus, J.S. (1997) The photochemical reflectance index: an optical indicator of photosynthetic radiation-use efficiency across species, functional types, and nutrient levels. Oecologia, 112,492-501.
Gamon, J.A., Penuelas, J. and Field, C.B. (1992) A narrow-waveband spectral index that tracks diurnal changes in photosynthetic efficiency. Remote Sens. Environ. 41,35- 44.

Gerard. F., Plummer. S., Wadsworth. R., Sanfeliu. A.F. and Iliffe. L. (2003) Forest Fire Scar Detection in the Boreal Forest With Multitemporal SPOTVEGETATION Data. IEEE Trans Geosci. Remote Sens. 41,2575-2585.

Gong P., Ruiliang P., Greg S. and Mirta R. (2003) Estimation of Forest Leaf Area Index Using Vegetation Indices Derived From Hyperion Hyperspectral Data. IEEE Transactions On Geoscience and Remote Sensing, 41, 1355-1362.

Haboudanea, D., Millera, J.R., Pattey, E., ZarcoTejadad, P.J. and Strachan, I.B. (2004) Hyperspectral vegetation indices and novel algorithms for predicting green LAI of crop canopies: Modeling and validation in the context of precision agriculture. Remote Sensing of Environment, 90, 337-352.

Hardisky, M.A., Klemas, V. and Smart, R.M. (1983) The Influence of Soil Salinity, Growth Form, and Leaf Moisture on-the Spectral Radiance of partina alterniflora Canopies. Photogramm Eng. Remote Sensing, 49,77-83.

He, Y.H., Guo, X.L. and Wilmshurst, J. (2006) Studying mixed grassland ecosystems I: suitable hyperspectral vegetation indices. Canadian Journal of Remote Sensing, 32,98-107.

Horler, D.N.H., Dockray, M. and Barber, J. (1983) The red-edge of plant leaf reflectance. International Journal of Remote Sensing, 4, 273-288.

Huete, A., Didan, K., Miura, T., Rodriguez, E.P., Gao, X. and Ferreira, L.G. (2002) Overview of the radiometric and biophysical performance of the MODIS vegetation indices. Remote Sens. Environ. 83,195-213.

Huete, A.R. (1988) A soil-adjusted vegetation index (SAVI). Remote Sens. Environ. 25,295-309.

Hunt, E.R. and Rock, B.N. (1989) Detection of changes in leaf water content using near and middle-infrared reflectances. Remote Sensing of Environment, 30, 43-54.

Jensen, J.R. (2000) Remote Sensing of the Environment: An Earth Resource Perspective. New Jersey, USA: Prentice Hall.

Kruse, F.A., Lefkoff, A.B., Boardman, J.W., Heidebrecht, K.B., Shapiro, A.T., Barloon, P.J.

Egypt. J. Soil Sci. 58, No. 1 (2018) 
and Goetz, A.F.H. (1993) The Spectral Image Processing System (SIPS). Interactive Visualisation and Analysis of Imaging Spectrometer Data. Remote Sensing of Environments, 44,145-163.

Lawrence, R.L. and Ripple, W.J. (1998) Comparisons among vegetation indices and bandwise regression in a highly disturbed, heterogeneous landscape:Mount St. Helens, Washington. Remote Sensing of Environment, 64, 91-102.

Mathur, A. and Foody, G.M. (2008) Crop classification by support vector machine withintelligently selected training data for an operational application. International Journal of Remote Sensing, 29, 2227 2240.

McFeeters, S.K. (1996) The use of the Normalized Difference Water Index (NDWI) in the delineation of open water features. Int. J. Remote Sens. 17,1425-1432.

Meroni, M., Colombo, R. and Panigada, C. (2004) Inversion of a radiative transfer model with hyperspectral observations for LAI mapping in poplar plantations. Remote Sens. Environ. 92,195206.

Merzlyak, M.N., Gitelson, A.A., Chivkunova, O.B. and Rakitin, V.Y. (1999) Non-destructive optical detection of leaf senescence and fruit ripening. Physiol. Plant. 106,135-141.

Musick, H.B. and Pelletier, R.E. (1986) Response of Some Thematic Mapper Band Ratios to Variation in Soil Water Content. Photogramm. Eng. Remote Sens. 52,1661-1668.

Penuelas, J., Baret, F. and Filella, I. (1995) Semiempirical indices to assess carotenoids/ chlorophyll a ratio from leaf spectral reflectance. Photosynthetica, 31, 221- 230.

Pu, R., Gong, P., Biging, G.S. and Larrieu, M.R. (2003) Extraction of red edge optical parameters from hyperion data for estimation of forest leaf area index. IEEE Trans. Geosci. Remote Sens. 41,916921

Qi, J., Chehbouni, A., Huete, A.R., Keer, Y.H. and Sorooshian, S. (1994) A modified soil vegetation adjusted index. Remote Sens. Environ. 48,119-126.

Read, J.J., Tarpley, L., Mc Kinion, J.M. and Reddy, K.R. (2002) Narrow waveband reflectance ratios for remote estimation of nitrogen status in cotton. J. Environ. Qual. 31,1442-1452.

Ren, H.R. and Zhou, G.S. (2012) Estimating senesced biomass of desert steppe in Inner Mongolia using field spectrometric data. Agricultural and Forest Meteorology, 161,66-71.

Ren H.R., Zhou G.S., Zhang X.S. (2011) Estimation of green aboveground biomass of desert steppe in Inner Mongolia based on red edge reflectance curve area method. Biosystems Engineering, 109,385395.

Rondeaux G., Steven M. and Baret F. (1996) Optimization of soil-adjusted vegetation indices. Remote Sensing of Environment, 55: 95-107.

Roujean J.L. and Breon E.M. (1995) Estmating PAR absorbed by vegetation from bibirectional reflectance measurements. Remote Sens. Environ. 51,375-384.

Schaepman, M.E. (2007) Spectrodirectional remote sensing: From pixels to processes. Int. J. Appl. Earth Obs. 9, 204-223.

Schlerf, M. (2011) Hyperspectral remote sensing applications for vegetation studies. . In :Ranganath R. Navalgund and Shibendu S. Ray (Ed.): Hyperspectral Data Analysis Techniques and Applications, Indian society of remote sensing., Dehradun:79-99.

Seelig, H.D., Hoehn, A., Stodieck, L., Klaus, D.M., Adams, W. and Emery, W.K. (2008) Relations of remote sensing leaf water indices to leaf water thickness in cowpea, bean, and sugarbeet plants. Remote Sens. Environ. 112,445-455.

Sellers, P.J. (1985) Canopy reflectance, photosynthesis and transpiration. International Journal of Remote Sensing, 6,1335-1372.

Shwetank, Jain K. and Bhatia K.F. (2010) Review of rice crop identification and classification using Hyper spectral image processing system. International Journal of Computer Science \& Communication, 1,253-258.

Sims, D.A. and Gamon, J.A. (2003) Estimation of vegetation water content and photosynthetic tissue area from spectral reflectance: a comparison of indices based on liquid water and chlorophyll absorption features. Remote Sensing of Environment, 84,526-537.

Stagakis, S., Markos, N., Sykioti, O. and Kyparissis, A. (2010) Monitoring canopy biophysical and biochemical parameters in ecosystem scale using satellite hyperspectral imagery: An application on a Phlomis fruticosa Mediterranean ecosystem

Egypt. J. Soil Sci. 58, No.1 (2018) 
using multiangular CHRIS/PROBA observations. Remote Sens. Environ. 114, 977-994.

Strachan, I.B., Pattey, E. and Boisvert, J.B. (2002) Impact of nitrogen and environmental conditions on corn as detected by hyperspectral reflectance. Remote Sens. Environ. 80,213- 224.

Thenkabail, P.S., Enclona, E.A., Ashton, M.S. and Meer, B.V.D. (2004) Accuracy assessments of hyperspectral waveband performance for vegetation analysis applications. Remote Sens. Environ. 91, 354-376.

Thenkabail, P.S., Isabella, M., Murali, K.G., Elizabeth, M.M., David, R.L. and Huemmrich, K.F. (2013) Selection of Hyperspectral Narrowbands (HNBs) and Composition of Hyperspectral Twoband Vegetation Indices (HVIs) for Biophysical Characterization and Discrimination of Crop Types Using Field Reflectance and Hyperion/EO-1 Data. IEEE Journal of Selected Topics in Applied Earth Observations and Remote Sensing, 6.

Thenkabail, P.S., Lyon, J.G. and Huete, A. (2011) Hyperspectral Remote Sensing of Vegetation. CRC Press:781.

Thenkabail, P.S., Smith, R.B. and De Pauw, E. (1999) Hyperspectral Vegetation Indices for Determining Agricultuml Crop Characteristics. CEO Research Publication Series \#I, ISBN: 0-9671303-0-1, Center for Earth Observation, Yale University, New Haven, Connecticut:47

Tian -Yuan, S. (2004) On the Atmospheric Correction for a Hyperion Scene. Department of Civil Engineering, National Chiao-Tung University Hsin-Chu, Taiwan.

Ustin, S.L., Gitelson, A.A., Jacquemoud, S., Schaepman, M., Asner, G.P., Gamon, J. A. and Zarco-Tejada, P. (2009) Retrieval of foliar information about plant pigment systems from high resolution spectroscopy. Remote Sensing of Environment, 113,S67-S77.

Venkataratnam, L. (2001) Remote sensing and GIS inagricultural resources management. Proceedings ofthe 1st National Conference on Agro-Informatics, June 3-4, Dharwad, India:20-29.

Vogelmann, J.E., Rock, B.N. and Moss, D.M. (1993) Red edge spectral measurements from sugar maple leaves. International Journal of Remote Sensing, 14,1563-1575.

Walsh, S.J., Amy, L.M., Carlos, F.M., Yang, S., Julie , P.T., Augusto, G. and Rachel, A. (2008) QuickBird and Hyperion data analysis of an invasive plant species inthe Galapagos Islands of Ecuador: implications for control and land use management. Remote Sensing of Environment, 112,1927-1941.

Wessels, S.D., Prince, S.D., Zambatis, N., Macfadyen, S., Frost, P.E. and Van Zyl, D. (2006) Relationship between herbaceous biomass and 1-km2 Advanced Very High Resolution Radiometer (AVHRR) NDVI in Kruger National Park, South Africa. International Journal of Remote Sensing, 27,951-973.

White, J. C. (2010) Characterising temperate forest structural and spectral diversity withHyperion EO-1 data. Remote Sensing of Environment, 114,1576-1589.

Wu, Y., Chen, J., Wu, X. and Tian, Q. (2005) Possibilities of reflectance spectroscopy for the assessment of contaminant elements in suburban soils. Applied Geochemistry, 20,1051-1059.

Xu, H. (2006) Modification of normalised difference water index (NDWI) to enhance open water features in remotely sensed imagery. Int. J. Remote Sens. 27,3025-3033.

Xu, H., Zhu, S., Ying, Y. and Jiang, H. (2006) Early detection of plant disease using infrared thermal imaging. Proc. SPIE 6381, Optics for Natural Resources, Agriculture, and Foods, 638110 doi:10.1117/12.685534.

Zarco-Tejada, P., Miller, J., Mohammed, G., Noland, T. (2000) Chlorophyll Fluorescence Effects on Vegetation: Apparent Reflectance: Leaf-Level Measurements and Model Simulation. Remote Sensing of Environment, 74,582-595.

Zarco-Tejada, P.J., Rueda, C.A., Ustin, S.L. (2003) Water content estimation in vegetation with MODIS reflectance data and model inversion methods. Remote Sensing of Environment, 85,109-124.

Zarco-Tejada, P.J., Ustin, S.L. and Whiting, M.L. (2005) Temporal and spatial relationship between within field yield variability in cotton and high spatial hyperspectral remote sensing imagery. Agronomy Journal, 97, 641-652.

Zhang, N., Yang, H., Qiming, Q. and Lin, Z. (2013) Evaluation of the Visible and Shortwave Infrared Drought Index in China. Int. J. Disaster Risk Sci. 4, 68-76.

(Received:17/10/2015

accepted: 4/11/2015)

Egypt. J. Soil Sci. 58, No. 1 (2018) 


\section{التعرفة فن بعدة علئة خصائص الغطاء النباتي باستخدام التصويرفوق الطيفي للزراعة}

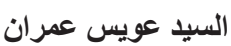

قسم الأراضي و المياه ـكلية الزر اعة - جامعة قناة السويس - الإسماعيلية ـ مصر.

لقد تم استخدم التصوير فوق الطيفيHyperspectral sensor كأداة لرصد وتقييم الأدلة النباتية والإجهاد

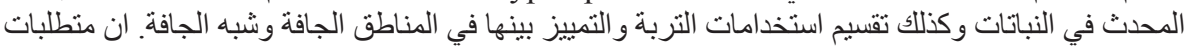

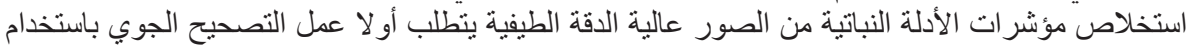

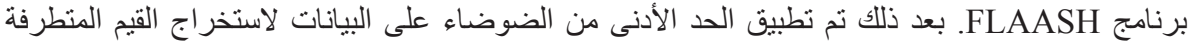

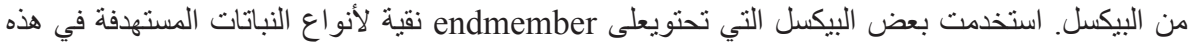

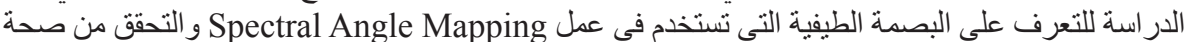

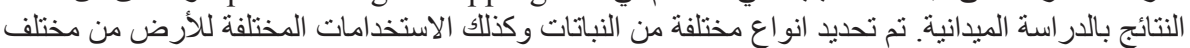

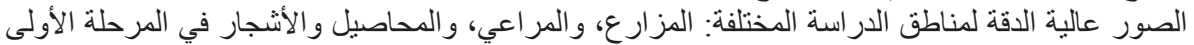

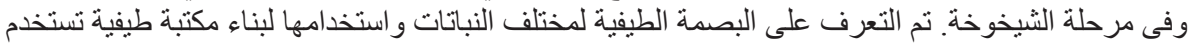

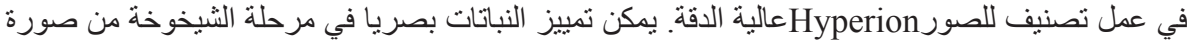
Hyperion

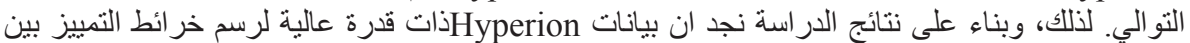

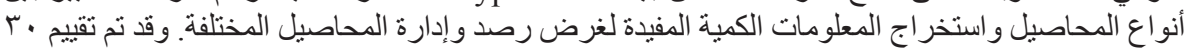

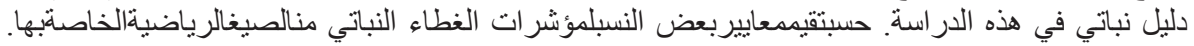

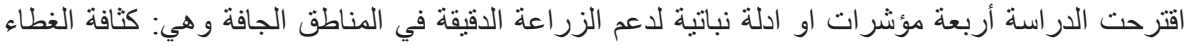

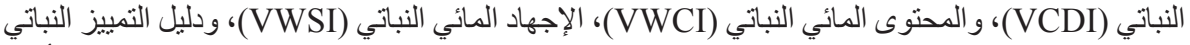

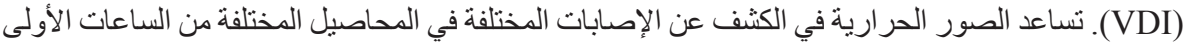

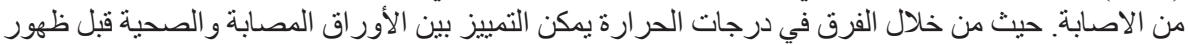

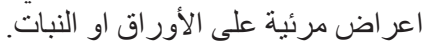

